\title{
The Effect of Firm Cash Holdings on Monetary Policy*
}

\author{
Bernardino Adão \\ Banco de Portugal
}

\author{
André C. Silva \\ Nova School of Business and Economics
}

December 2016

\begin{abstract}
Firm cash holdings increased substantially from 1980 to 2013. The overall distribution of firm cash holdings changed in the same period. We study the implications of these changes for monetary policy. We use Compustat data and a model with financial frictions that allows the calculation of the monetary policy effects according to the distribution of cash holdings. We find that the interest rate channel of the transmission of monetary policy has become more powerful, as the impact of monetary policy over real interest rates increased. With the observed changes in firm cash holdings, the real interest rate takes 3.4 months more to return to its initial value after a shock to the nominal interest rate.
\end{abstract}

JEL classification: E40, E50, G12, G31.

Keywords: firm cash holdings, interest rates, financial frictions, market segmentation, liquidity effect, monetary policy.

*Adão: Banco de Portugal, DEE, Av. Almirante Reis 71, Lisbon, Portugal, 1150021, badao@bportugal.pt. Silva: Nova School of Business and Economics, Universidade Nova de Lisboa, Campus de Campolide, Travessa Estevao Pinto, Lisbon, Portugal, 1099-032, andre.silva@novasbe.pt. The views in this paper are those of the authors and do not necessarily reflect the views of the Banco de Portugal. We thank Heitor Almeida, Rui Albuquerque, Philippe Bacchetta, Marco Bassetto, Thomas Bates, Paco Buera, Jeffrey Campbell, Isabel Correia, Igor Cunha, Carlos da Costa, Miguel Ferreira, Francesco Lippi, Ana Marques, Ed Nosal, Luigi Paciello, and participants at various seminars for valuable comments and discussions. We acknowledge financial support from ADEMU and FCT PTDC/IIM-ECO/4825/2012. Silva thanks the hospitality of the Banco de Portugal, where he wrote part of this paper, and acknowledges financial support from Banco de Portugal, NOVA FORUM, and NOVA Research Center. 


\section{Introduction}

We obtain predictions for the effect on monetary policy of the changes in the distribution of corporate cash holdings. Bates et al. (2009), Bover and Watson (2005) and others noticed the increase in corporate cash holdings since 1980, both in real terms and as a percentage of total cash. Corporate cash holdings corrected for inflation increased five times from 1980 to 2010. The median cash-sales ratio increased from $3 \%$ in 1980 to $12 \%$ in 2010 . The mean cash-sales ratio increased from $6 \%$ to $23 \%$ during the same period. ${ }^{1}$ Corporate cash holdings, measured as cash and equivalents of the U.S. nonfinancial firms listed in Compustat, amounted to 1.56 trillion dollars in 2010. As M1 amounted to 1.84 trillion, according to data from the St. Louis Fed, 1.56 trillion dollars corresponds to $85 \%$ of M1. The ratio of corporate cash holdings decreased from 2010 to 2013, as M1 has increased sharply more recently. Even so, corporate cash holdings to M1 was equal to $65 \%$ in 2013. This ratio was $29 \%$ in 1980 and $85 \%$ in 2010. As the demand for money from corporations is substantial, changes in corporate cash holdings can affect monetary aggregates and monetary policy significantly. ${ }^{2}$

Our objective is to analyze the implications of the secular increase in corporate cash holdings on the effects of monetary policy. We find that the real interest rate takes 3.4 more months in 2013 than in 1980 to revert to its initial value after a

\footnotetext{
${ }^{1}$ Bates et al. (2009) concentrate on the cash-assets ratio, which shows a similar increase over time. As it will be clear when we introduce the model, it is more appropriate for our purposes to use the cash-sales ratio.

${ }^{2}$ We restrict our sample to firms with positive cash, positive assets, assets greater than cash, and sales greater than 10 million (CPI adjusted with base 1982-1984). We also truncated the firms at the 1 and 99 percentiles of the cash-sales ratio. With the less stringent constraint of sales greater than zero, the increase in the median cash-sales ratio is from $3.5 \%$ to $13.4 \%$, an increase of 3.8 times. There are different measures of cash holdings such as the cash-assets and the cash-net assets ratio. We use the cash-sales ratio because it has a better data counterpart to the variables in the model. We explain this variable in more detail in section 2.
} 
nominal interest rate shock. A consequence of this result is that, given the large current firm cash holdings, an increase in interest rates today has a higher impact on real interest rates. To obtain our findings, we use a model that simulates the effects on the real interest rate of a nominal interest rate shock. The main characteristic of the model is that it takes into account the observed distribution of money holdings over time. According to the model, the real interest rate takes 1.84 months to revert to its initial value with the distribution of money holdings of 1980, while with the 2013 distribution of money holdings, the real interest rate takes 5.25 months to revert to its initial value. Figure 1 shows how long the real interest rate takes to return to its initial value from 1980 to 2013 according to our simulations.

The increase in firm cash holdings is related with the declining trend in the opportunity cost of cash. ${ }^{3}$ The Aaa corporate bond yield decreased from $12 \%$ in 1980 to $4 \%$ in 2013 and the Baa corporate bond yield for the same period decreased from $14 \%$ to $5 \%$. The opportunity cost of money is important to explain the evolution of firms cash holdings. Figure 2 shows Aaa corporate bond yields and various measures of real cash. The elasticity of real cash holdings with respect to yields is clearly negative, with absolute values greater than 1 and highly significant. ${ }^{4}$

We study the implications of the increase in corporate cash holdings on the effects of monetary policy. ${ }^{5}$ As firms hold a large portion of the monetary aggregates, it

\footnotetext{
${ }^{3}$ There is a large literature on the determinants of firm cash holdings. Among the explanations for firm cash holdings, a partial list includes the transactions role of cash (Baumol 1952, Tobin 1956, Miller and Orr 1966, Frenkel and Jovanovic 1980), financial constraints (Almeida et al. 2004, Acharya et al. 2007), tax purposes (Foley et al. 2007), agency problems (Kalcheva and Lins 2007), and corporate governance (Jensen 1986, Blanchard et al. 1994, Dittmar et al. 2003, Pinkowitz et al. 2006, Dittmar and Mahrt-Smith 2007, Harford et al. 2008, Yun 2009, Bates et al. 2009). Empirically, the different determinants of firm cash holdings are analyzed by Kim et al. (1998), Opler et al. (1999), and Ozkan and Ozkan (2004).

${ }^{4}$ Figure A.1 in the appendix shows cash holdings over time together with Aaa and Baa Moody's corporate bond yields.

${ }^{5}$ We analyze how changes in firm cash holdings affect macroeconomic variables. Fresard (2010)
} 
is important to study the effects of the increase in cash holdings on macroeconomic variables. To the best of our knowledge, we are the first to study the consequences of the changes in the distribution of corporate cash for monetary policy. ${ }^{6}$ A related paper is Cole and Ohanian (2002), which studies how shifts in the demand for money affect the macroeconomic impact of monetary shocks. We emphasize here the changes in the distribution of cash holdings across firms. Cole and Ohanian (2002) find that changes in the relative demands for money between households and firms have quantitatively important macroeconomic effects in a liquidity model. ${ }^{7}$

As we are interested in the effects of the distribution of money holdings, we use a model in which the distribution of money holdings plays an active role. In the first cash-in-advance models such as Lucas and Stokey (1987), Cooley and Hansen (1989), and Hodrick et al. (1991), the distribution of money holdings is degenerate. All participants in the economy behave as a representative agent and they have the same demand for money. We cannot evaluate the impact of the distribution of money with these models because they do not allow any role for the distribution of money.

More recently, the real effects of monetary policy have been studied in new Keynesian models (for example, Clarida et al. 1999, Woodford 2003, and Christiano et al. 2005). These models contain frictions usually in the form of price rigidities. There is a distribution of prices across firms, but the distribution of money is again degenerate. A representative agent uses all money carried from the last period to buy

and Palazzo (2012) study the real effects of cash holdings on market share and equity returns.

${ }^{6} \mathrm{~A}$ recent paper that studies the interaction of firm cash holdings and macroeconomic variables is Bacchetta, Benhima, and Poilly (2014).

${ }^{7}$ Cole and Ohanian do not confirm major changes in the effects of money shocks over the postwar period, as indicated with VARs. However, as Chari, Kehoe and McGrattan (2008) point out, the procedure of comparing impulse responses from structural VARs to the theoretical impulse responses from models and rejecting the model if they are different can be misleading. In particular, this procedure cannot be used to reject the liquidity model, as liquidity models do not satisfy the set of identifying assumptions in VARs. 
products in the current period. As in the cash-in-advance models, the distribution of money holdings in these models does not affect the results of monetary policy. Other kinds of frictions, such as informational frictions (Mankiw and Reis 2002) and menu costs (Golosov and Lucas 2007), have also been introduced to study the real effects of monetary policy. Alternatively, Stein (1998), Kashyap and Stein (2000), and Bolton and Freixas (2006) focused on the role of bank lending.

Here, to take into account the effects of changes in the distribution of cash holdings, we use a market segmentation model. The friction in this kind of model is the separation of markets for liquid and illiquid assets. Liquid assets are used for transactions while illiquid assets receive higher interest yields and are kept mainly as a reserve of value. These markets are separated in the sense that firms cannot exchange illiquid assets for cash with a high frequency.

We modify the models in Alvarez et al. (2009) and Silva (2012) to match the observed distribution of firm cash holdings in the data. Alvarez et al. (2009) show that the model closely matches the short-run fluctuations in velocity. Here, we use the model to obtain a prediction about the effects of the increase in cash holdings. The prediction is obtained by calculating the response of the real interest rate to a nominal interest rate shock for each year from 1980 to 2013. Our model delivers closed-form solutions for each nominal interest shock. The shocks follow the interest rate dynamics in Christiano et al. (1999) and Uhlig (2005). For each year, we recalibrate the model to fit the distribution of cash holdings. As the distribution of cash holdings changes, the response of the real interest rate changes.

The real effects occur because the behavior of firms with respect to the use of cash depends on their cash holdings at the time of the shock. Firms with little cash adapt faster to the shock while firms with large cash holdings take longer to adapt. If the market segmentation friction is removed, the real interest rate does not move 
after the shock and the real effects vanish. As we want to isolate the effects of the change in cash holdings, we eliminate other mechanisms besides market segmentation that could generate additional real effects. In particular, there are no sticky prices, output is constant, and the only change in the economy during the period is in the distribution of cash holdings. The changes in firm characteristics during the period are reflected in the distribution of cash holdings.

Firms undertake infrequent portfolio rebalancing, as they exchange bonds for cash infrequently. Therefore, another way of understanding the causes of the real effects of monetary shocks in the model is through the infrequent portfolio rebalancing. As firms do not rebalance their portfolios instantaneously, they do change their behavior immediately when there is a monetary policy shock. This delayed effect is more pronounced when firms maintain larger amounts of cash. ${ }^{8}$

In the data, there is a nondegenerate cross-sectional distribution of cash. Certainly, different firm characteristics, such as their business and corporate governance, are reflected in their behavior toward cash management. Heterogeneity across cash holdings changes the speed and the size of the adjustment to the shock. If all firms held the same amount of cash, the mean level, for instance, then monetary shocks would have different real effects. This property is not unique to our model, the new Keynesian Phillips curve model shares this property. Carvalho and Nechio (2011) show that heterogeneity in the price setting behavior of firms implies aggregate dynamics substantially different from the case when all firms have the same price setting behavior. Here, after the shock hits the economy, the initial phase of the adjustment process is driven mainly by the set of firms with less cash. The later part of the

\footnotetext{
${ }^{8}$ The impact of infrequent portfolio rebalancing has also been studied by Bacchetta and van Wincoop (2010) to analyze the forward premium puzzle. Bachmann and Ma (2016) study fixed costs and investment dynamics. This literature is related to the separation of microeconomic and macroeconomic behavior caused by fixed adjustment costs.
} 
adjustment process is dominated by the set of firms with larger stocks of cash.

We find that the effects of monetary policy over the real interest rate are now more persistent than in 1980, as there has been a substantial increase in cash holdings by firms since then. The effects of monetary policy shocks become stronger, as monetary authorities have more ability to affect real variables. Consistent with this idea, Clarida et al. (2000) state that monetary policy has been more effective after 1980.

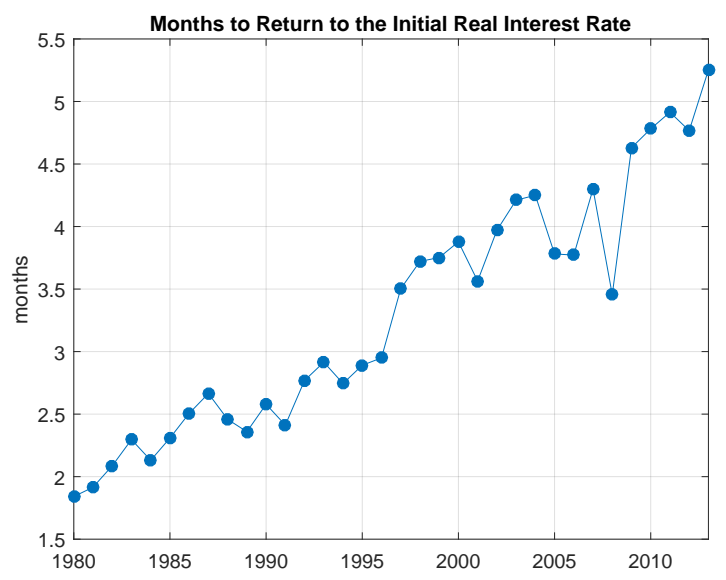

FIG. 1: Simulations with the model of section 3 for a given nominal interest rate shock. The simulations take into account the distribution of the cash-sales ratio for each year.

\section{The Distribution of Cash Holdings over Time}

Figure 3 shows the median and the mean of the cash-sales ratio from 1980 to 2013. Different measures of cash have been used to analyze firm cash holdings such as the cash-net assets ratio (used, for example, by Opler et al. 1999) and the cash-assets ratio (by Bates et al. 2009). The cash-sales ratio has been used, among others, by Mulligan (1997), Harford (1999), Harford et al. (2008), and Bover and Watson (2005). Both, the cash-assets ratio and the cash-sales ratio, have been increasing 

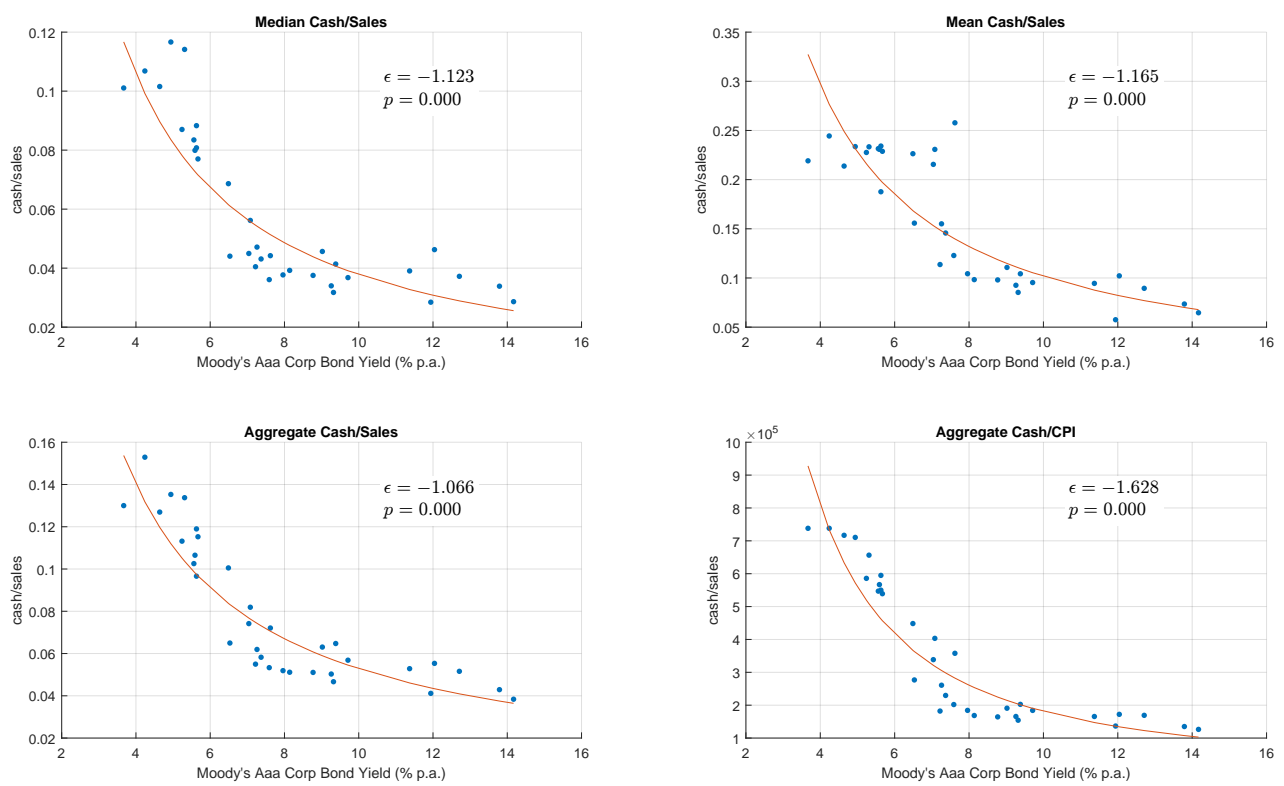

FIG. 2: Corporate bond yields and different measures of firm real cash holdings. $\epsilon$ denotes elasticities and $p$ denotes p-values. Annual data 1980-2013. Data on yields and CPI from the St. Louis Fed FRED dataset. Data on cash and sales from Compustat.

substantially over time. The cash-assets ratio indicates the way in which a firm allocates cash in its portfolio of assets. The cash-sales ratio indicates how much cash a firm holds with respect to the flow of resources obtained with its operations. It has a more direct interpretation in terms of the use of cash for transactions. The conclusions of this paper are robust to the use of one measure or the other. We use the cash-sales ratio because its interpretation - cash relative to the flow of resources obtained - allows a better connection between the model parameters and the data. ${ }^{9}$

\footnotetext{
${ }^{9}$ Our measure of cash is cash and equivalents from Compustat, "cash and short-term investments," CHE, U.S. nonfinancial firms. CHE is not available for utilities, so the dataset removes this sector. To avoid anomalies, we remove observations with cash or assets equal to zero, and observations with cash greater than assets. To avoid extreme cash-sales ratios, we remove observations with sales smaller than 10 million and observations with cash/sales below the 1st and above the 99th percentiles of cash/sales. We later report results without this truncation, which barely changes results. We correct for inflation with the CPI from the St. Louis Fed FRED dataset, CPIAUCSL, base 1982-84. For sales, we use SALE in Compustat. Our procedure implies 140,435 firm-years or about 4,130 firms per year.
} 
As cash is measured in dollars and sales is measured in dollars per unit of time, the cash-sales ratio is a variable given in units of time. The median cash-sales ratio of 0.12 year in 2010, for example, means that firms maintained about 1.4 months of their sales in the form of cash. In 1980, this same ratio was only 0.03 , or 11 days. The mean cash-sales ratio in the same period increased from 0.06 in 1980 to 0.23 in 2010. The distribution of the cash-sales ratio across firms is highly asymmetric as it can be inferred by the difference between its mean and median. The mean was more than two times the median during the whole period and it reached 5.8 times the median in 2000 .

If there were no benefits of maintaining cash, firms would choose a cash-sales ratio approximately equal to zero. In this way, firms would minimize the opportunity cost of holding cash. As the cash-sales ratio is large, the data indicate the existence of costs in the management of money. These costs may be in the form of transaction costs or in the form of management costs. A portfolio manager, for example, may schedule sales of long term bonds to coincide with cash needs. However, this schedules of payments or other more elaborate mechanisms to economize on cash are costly. It does not matter the nature of the costs of managing cash holdings for our purposes. What is important is that firm cash holdings are considerable. We take the values of firm cash holdings as given.

Usually, firms maintain cash-sales ratios smaller than one. The 95th percentile of the distribution of the cash-sales ratio reached a maximum of 1.3 in 2000 and it was about 1 during 2002-2007. A cash-sales ratio above one means that a firm keeps more than one year of sales in the form of cash. Firms that maintain high cash-sales ratios tend to be smaller firms in terms of sales; the same is true for the cash-assets ratio. Figure 4 shows the median of the cash-sales ratio over the same period for firms grouped in percentiles of sales. We see that the cash ratio increased for all 


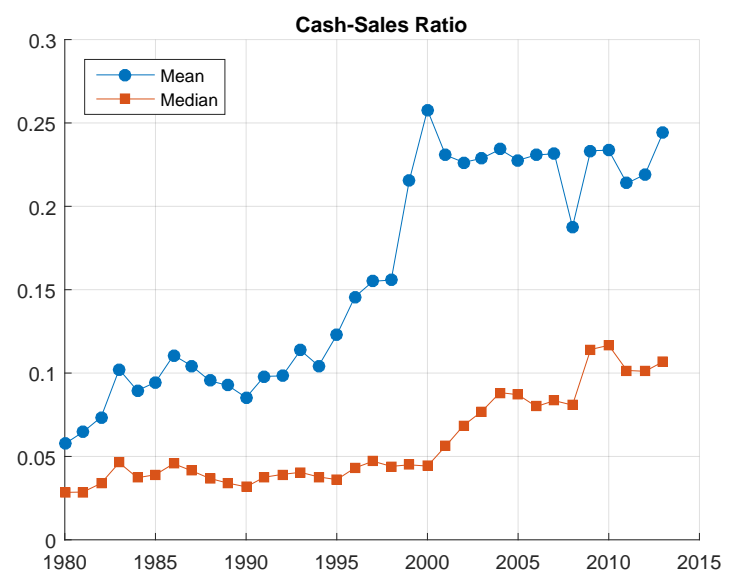

FIG. 3: Mean and median of the cash-sales ratio across firms for each year. The cash-sales ratio state how much firms maintain of their sales in cash. A cash-sales ratio of 0.1 , for example, means that firms maintain 10 percent of their yearly sales, or 1.2 months of sales, in cash. Source: Compustat; see note 9 for details.

groups. Moreover, while the cash ratio increased 3 times for all firms as a whole, it increased 5 times for firms in the smaller percentiles. Bates et al. (2009) show a similar evolution for the cash-assets ratio.

In addition to the increase in the cash-sales ratio, firm cash holdings correspond to a large fraction of the monetary aggregates and this fraction has increased substantially. From 1980 to 2010, the ratio between firm cash holdings to M1 increased from 30 percent to 85 percent. This fraction decreased to 65 percent in 2013 , still more than two times the ratio in 1980. As we show in this paper, a consequence of the increase in the proportion of firm cash holdings over monetary aggregates is that monetary policy has a much stronger effect than it had in the past. ${ }^{10}$

\footnotetext{
${ }^{10} \mathrm{M} 1$ is defined as currency plus traveler checks plus checkable deposits. In January 2014, currency corresponds to $43.6 \%$ of M1 and checkable deposits to $56.3 \%$. The definition of cash and equivalents in Compustat includes the components of M1 and "securities readily transferable to cash," which includes short term commercial paper, short term government securities, and money market funds. In our sample, the cash portion of cash and equivalents correspond on average to $70 \%$ of cash and equivalents.
} 


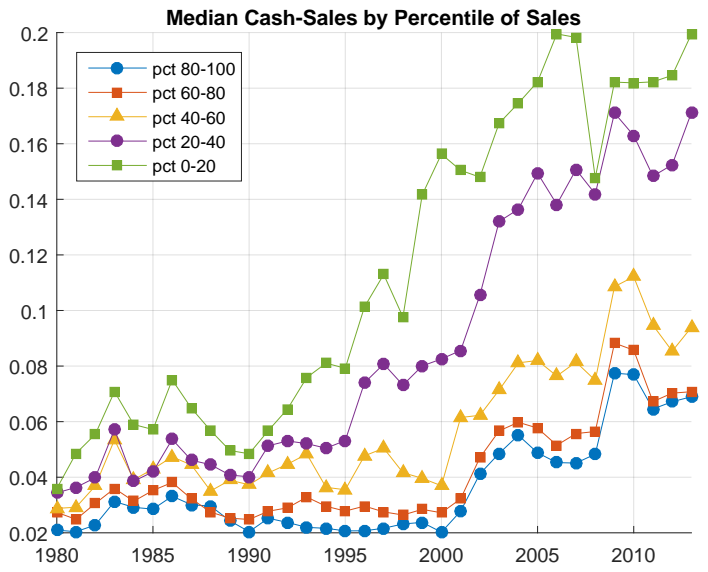

FIG. 4: Median of the cash-sales ratio for different percentiles of sales. Source: Compustat; see note note 9 for details.

Figure 5 shows the distribution of the cash-sales ratio for each year. The distributions look symmetric because the figure shows the logs of the cash-sales ratio. The support and the median of the distribution of the cash-sales ratio increased during the period. The support of the distribution increased first and the median increased later. In 1980, the maximum cash-sales ratio was equal to 7 months, that is, below one year. The maximum cash ratio was above 1 year after 1983 . In 2000, the maximum cash ratio was 5 years (the 95 th percentile was 1.3). Figure 3 shows that the increase in the median of the cash ratio accelerated after 2000 and figure 5 shows that the distribution of cash holdings changed substantially after this date. The two figures complement each other as they show that firm cash holdings changed especially after 2000 .

As figure 5 shows, the distribution of cash holdings across firms is not uniform; it is far from degenerate; and it has changed over time. Our objective is to calculate the predictions of the effects of monetary policy shocks under different distributions of cash holdings. In order to do so, we need a model that takes into account the 


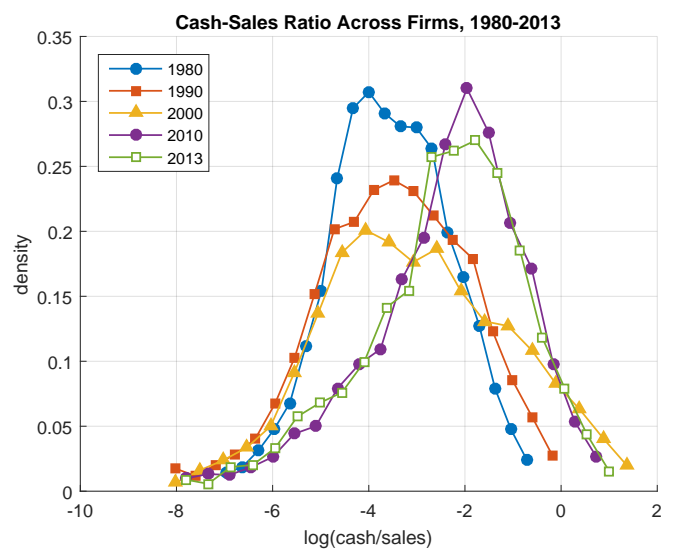

FIG. 5: Distribution of the cash-sale ratio across firms from 1980 to 2013 for selected years. Each curve has the distribution for one year (density histograms with 20 groups). The curves are approximately symmetric because it shows the logs of the cash-sales ratio; the actual distributions are highly asymmetric. Over the years, the support and the median of the cash-sales ratio increased. Source: Compustat; see note 9 for details.

different distributions of cash holdings. We introduce this model in the next section.

\section{The Model}

The model combines the cash inventory framework analyzed by Baumol (1952) and Tobin (1956) with the market segmentation framework introduced by Grossman and Weiss (1983), Rotemberg (1984), and later studied, among others, by Grossman (1987), Alvarez et al. (2009), and Silva (2012). ${ }^{11}$

The economy is composed by heterogeneous infinitely lived entrepreneurs. Each entrepreneur owns one firm, which produces the consumption good. The entrepreneurs produce, consume, borrow and hold cash. They are heterogeneous with respect to sales, bond and cash holdings. The entrepreneurs smooth their consumption using cash and non contingent bonds. Unlike bonds, cash pays no interest, but consump-

\footnotetext{
${ }^{11}$ In Silva (2012), money is held for transactions and velocity is allowed to vary according with the opportunity cost of money. This can explain the upward trend in firm cash holdings. Here, we use it mainly to assess the short-run effects of a change in the nominal interest rate.
} 
tion must be paid out with cash.

There is market segmentation between the goods market and the assets market. Each firm has a bank account and a brokerage account. The bank account is used to hold cash for transactions in the goods market. The brokerage account is used to hold bonds. Market segmentation implies that entrepreneurs sell bonds for money and transfer the proceeds periodically from the assets market to the goods market, where they buy the consumption good. The opportunity cost of cash, the interest rate, determines the size of cash transfers, or equivalently the duration of the holding period, which is the elapsed time between cash transfers. ${ }^{12}$

As different types of firms in the economy have different average cash holdings we allow for distinct groups of firms in the model, each one with a different holding period. In this way, we can better match the distribution of firms' cash holdings observed in the data, which is given by figure 5. The groups of firms are indexed by $i=1, \ldots, I$. The size of each group of firms is given by $v_{i}$, where $\sum_{i=1}^{I} v_{i}=1$, and the holding period for the firms that belong to group $i$ is denoted by $N_{i}$. The firms in group $i$ are distributed uniformly over the interval $\left[0, N_{i}\right)$, for $i=1, \ldots, I$, with $N_{i}<N_{i+1}$, for $i=1, \ldots, I-1$. Alvarez et al. (2009) and Grossman (1987) also dispose agents uniformly over the holding period, but they only consider one group of firms, i.e. one holding period size. In contrast, we allow for various holding periods with sizes $\left\{N_{i}\right\}_{i=1}^{I}$.

Time is continuous, $t \geq 0$. Let $M_{0 i}$ denote cash holdings at $t=0$ of firms in the

\footnotetext{
${ }^{12}$ The model is related to Silva (2012) and Adao and Silva (2015). In these papers, there is an explicit cost of transferring money from the assets market to the goods market and the holding period is obtained endogenously. Here, we abstract from this cost, and set the holding period exogenously, as we focus on the short-run dynamics of a small change in the nominal interest rate. It is assumed implicitly that the short-run dynamics will not affect the holding periods in an important way. Alvarez et al. (2009) also keep holding periods fixed in the short run. Our modifications imply closed-form solutions for the effects of shocks.
} 
group $i$ and let $B_{0 i}$ denote bond holdings at $t=0$ of firms in the group $i$. Each firm, $s_{i}$, is identified by its initial portfolio, i.e. $s_{i} \equiv\left(M_{0 i}, B_{0 i}\right)$. Firms in group $i$ produce $Y_{i}$ goods at time $t$ and obtain $P(t) Y_{i}$ of sales at time $t$, where $P(t)$ denotes the price level at time $t$. The proceeds of sales are deposited directly in the brokerage account and converted into bonds. The price of bonds at time $t$ is given by $Q(t)$, with $Q(0)=1$. The nominal interest rate is $r(t) \equiv-d \log Q(t) / d t$.

Let $T_{j i}\left(s_{i}\right)$, for $j=1,2, \ldots$, denote the times of the transfers of firm $s_{i}$, and define $T_{0 i}\left(s_{i}\right) \equiv 0$, as that will simplify the notation later. Thus, at $T_{j i}\left(s_{i}\right)$, for $j=1,2, \ldots$, firm $s_{i}$ sells bonds for money and transfers the proceeds to the goods market (to its bank account). The $j$ th holding period of firm $s_{i}$ is $\left[T_{j, i}\left(s_{i}\right), T_{j+1, i}\left(s_{i}\right)\right)$, for $j=1,2, \ldots$. We have $T_{j+1, i}-T_{j, i}=N_{i}$ for $j=1,2, \ldots$ for all $s_{i}$ firms, with $i=$ $1, \ldots, I$. Cash holdings are denoted by $M\left(t, s_{i}\right)$. Cash just after a transfer is denoted by $M^{+}\left(T_{j i}\left(s_{i}\right), s_{i}\right)$ and is equal to $\lim _{t \rightarrow T_{j i}, t>T_{j i}} M\left(t, s_{i}\right)$. Analogously, cash just before a transfer is denoted by $M^{-}\left(T_{j i}\left(s_{i}\right), s_{i}\right)$ and is equal to $\lim _{t \rightarrow T_{j i}, t<T_{j i}} M\left(t, s_{i}\right)$. The transfer amount from the brokerage account to the bank account is given by $M^{+}-M^{-}$. Similarly, bonds just before a transfer and just after a transfer are given by $B^{-}\left(T_{j i}\left(s_{i}\right), s_{i}\right)$ and $B^{+}\left(T_{j i}\left(s_{i}\right), s_{i}\right)$, respectively. If the amount of cash transferred to the bank account is positive, then $B^{-}>B^{+}$. Cash holdings in the brokerage account are zero, as cash does not receive interest and it is not possible to purchase goods with the cash in the brokerage account. Firms keep bonds in the brokerage account and make periodical transfers to the bank account in order to make transactions.

We formalize the problem of entrepreneur $s_{i}$, who starts with assets $\left(M_{0 i}, B_{0 i}\right)$, receives a flow of funds $P(t) Y_{i}$ in the brokerage account, and aims to achieve an optimal amount of transactions $c_{i}\left(t, s_{i}\right)$. Because it simplifies the analysis we take that the objective function of the entrepreneur to be logarithmic in the amount of 
transactions. The logarithmic utility allows us to obtain analytical solutions for the dynamics of the real interest rate after shocks.

The problem of entrepreneur $i$ 's is to choose transactions $c_{i}\left(t, s_{i}\right), \operatorname{cash} M_{i}\left(t, s_{i}\right)$, and bonds $B_{i}\left(t, s_{i}\right)$ such that

$$
\max _{\left\{c_{i}, B_{i}, M_{i}\right\}} \sum_{j=0}^{\infty} \int_{T_{j i}\left(s_{i}\right)}^{T_{j+1, i}\left(s_{i}\right)} e^{-\rho t} \log \left(c_{i}\left(t, s_{i}\right)\right) d t
$$

subject to

$$
\begin{gathered}
M_{i}^{+}\left(T_{j i}\left(s_{i}\right)\right)+B_{i}^{+}\left(T_{j i}\left(s_{i}\right)\right)=M_{i}^{-}\left(T_{j i}\left(s_{i}\right)\right)+B_{i}^{-}\left(T_{j i}\left(s_{i}\right)\right), j=1,2, \ldots \\
\dot{B}_{i}\left(t, s_{i}\right)=r(t) B_{i}\left(t, s_{i}\right)+P(t) Y_{i}, t \geq 0, t \neq T_{1 i}\left(s_{i}\right), T_{2 i}\left(s_{i}\right), \ldots, \\
\dot{M}_{i}\left(t, s_{i}\right)=-P(t) c_{i}\left(t, s_{i}\right), t \geq 0, t \neq T_{1 i}\left(s_{i}\right), T_{2 i}\left(s_{i}\right), \ldots,
\end{gathered}
$$

with $M_{i}\left(t, s_{i}\right) \geq 0, c_{i}\left(t, s_{i}\right) \geq 0$, given $M_{0 i}\left(s_{i}\right)$ and $B_{i}\left(t, s_{i}\right)$, and where $\rho>$ 0 is the rate of intertemporal discounting. At $t=T_{1 i}\left(s_{i}\right), T_{2 i}\left(s_{i}\right), \ldots$, we have $\dot{B}_{i}\left(T_{j i}\left(s_{i}\right), s_{i}\right)^{+}=r(t) B_{i}^{+}\left(T_{j i}\left(s_{i}\right), s_{i}\right)+P(t) Y_{i}$, where $\dot{B}_{i}\left(T_{j i}\left(s_{i}\right), s_{i}\right)^{+}$is the right derivative of $B_{i}\left(t, s_{i}\right)$ with respect to time at $t=T_{j i}\left(s_{i}\right)$. Similarly, at $t=T_{1 i}\left(s_{i}\right)$, $T_{2 i}\left(s_{i}\right), \ldots, \dot{M}_{i}\left(T_{j i}\left(s_{i}\right), s_{i}\right)^{+}=-P(t) c_{i}^{+}\left(T_{j i}\left(s_{i}\right), s_{i}\right)$, where $\dot{M}_{i}\left(t, s_{i}\right)^{+}$is the corresponding right derivative for cash and $c_{i}^{+}\left(T_{j i}\left(s_{i}\right), s_{i}\right)$ are transactions just after the transfer. The solution to this problem minimizes the cost of holding cash over holding periods.

Using (3), we can write $B_{i}^{-}\left(T_{j i}\right)$ as a function of the interest payments accrued during $\left[T_{j-1}, T_{j}\right)$. Substituting recursively in (2), and using the no-Ponzi condition 
$\lim _{j \rightarrow+\infty} Q\left(T_{j}\right) B_{i}^{+}\left(T_{j i}\right)=0$, we obtain the present value budget constraint

$$
\sum_{j=1}^{\infty} Q\left(T_{j i}\left(s_{i}\right)\right) M_{i}^{+}\left(T_{j i}\left(s_{i}\right), s_{i}\right) \leq \sum_{j=1}^{\infty} Q\left(T_{j i}\left(s_{i}\right)\right) M_{i}^{-}\left(T_{j}\left(s_{i}\right), s_{i}\right)+W_{0 i}\left(s_{i}\right)
$$

where $W_{0 i}\left(s_{i}\right) \equiv B_{0 i}\left(s_{i}\right)+\int_{0}^{\infty} Q(t) P(t) Y_{i} d t$. Constraint (5) states that the present value of cash transfers is equal to the initial bonds plus the present value of deposits in the brokerage account.

To minimize the cost of holding money, firms make transfers and use cash during the holding periods so that $M_{i}^{-}\left(T_{j+1, i}\right)=0$. Cash transfers are just enough for the transactions during the holding period. Only $M_{i}^{-}\left(T_{1, i}\right)$ might be positive because $M_{0 i}$ is given. As $M_{i}^{-}\left(T_{j i}\right)=0$, for $j \geq 2$, then, from (4), cash at time $t$ is given by $M_{i}\left(t, s_{i}\right)=\int_{t}^{T_{j+1, i}\left(s_{i}\right)} P(\tau) c_{i}\left(\tau, s_{i}\right) d \tau$, for $T_{j i}\left(s_{i}\right) \leq t<T_{j+1, i}\left(s_{i}\right), j=1,2, \ldots$ Cash at the beginning of a holding period is given by

$$
M_{i}^{+}\left(T_{j i}\left(s_{i}\right), s_{i}\right)=\int_{T_{j, i}\left(s_{i}\right)}^{T_{j+1, i}\left(s_{i}\right)} P(\tau) c_{i}\left(\tau, s_{i}\right) d \tau, j=1,2, \ldots
$$

Below, instead of solving the problem of maximizing (1) subject to (2)-(4), we consider the simpler problem of maximizing (1) subject to the cash in advance constraint for the first period

$$
\int_{0}^{T_{1, i}\left(s_{i}\right)} P(\tau) c_{i}\left(\tau, s_{i}\right) d \tau+M_{i}^{-}\left(T_{1 i}\left(s_{i}\right)\right) \leq M_{0 i}\left(s_{i}\right)
$$

and to (5), where $M_{i}^{+}\left(T_{j i}\left(s_{i}\right), s_{i}\right)$ is replaced by the right hand side of $(6)$. The transactions, $c_{i}\left(t, s_{i}\right)$, and cash, $M_{i}^{-}\left(T_{1 i}\left(s_{i}\right)\right)$, that solve this simpler problem can be replaced in (2) and (3) to obtain the bonds, $B_{i}\left(t, s_{i}\right)$.

The government executes monetary policy through open market operations in 
the assets market. The government supplies aggregate cash $M(t)$. An increase in the supply of cash generates revenue $\dot{M}(t) / P(t)$. We abstract from government consumption or taxes to concentrate on the effects of monetary policy. Thus, the government budget constraint is given by $B_{0}^{G}=\int_{0}^{\infty} Q(t) \dot{M}(t) d t$, where $B_{0}^{G}$ is the aggregate supply of government bonds.

The market clearing condition for cash is given by $\sum_{i} v_{i} \int M_{i}\left(t, s_{i}\right) d F\left(s_{i}\right)=$ $M(t)$, where $F$ is the distribution of $s_{i}$. As stated above, $F\left(s_{i}\right)$ is an uniform distribution over $\left[0, N_{i}\right)$, for $i=1, \ldots, I$. Similarly, the market clearing conditions for bonds and goods are given by $B_{0}^{G}=\sum_{i} v_{i} \int B_{0 i}\left(s_{i}\right) d F\left(s_{i}\right)$ and $\sum_{i} v_{i} \int c_{i}\left(t, s_{i}\right) d F\left(s_{i}\right)=Y$, respectively.

The equilibrium is defined as a vector of prices $\{P(t), Q(t)\}$, and allocations $\left\{M_{i}\left(t, s_{i}\right), B_{i}\left(t, s_{i}\right), c_{i}\left(t, s_{i}\right)\right\}_{i=1}^{I}$ such that $\left\{M_{i}\left(t, s_{i}\right), B_{i}\left(t, s_{i}\right), c_{i}\left(t, s_{i}\right)\right\}_{i=1}^{I}$ solves the maximization problems (1)-(4) given $\{P(t), Q(t)\}$ for all $s_{i}$ in the support of $F\left(s_{i}\right)$; the government budget constraint holds; and the market clearing conditions for cash, bonds, and goods hold.

\section{The Distribution of Cash Holdings}

We characterize in this section the steady state equilibrium of the economy, that is, the equilibrium in which the inflation rate and the interest rate are constant. In the next section, we study the effects of a monetary shock when the economy is initially in the steady state.

As long as there is a positive opportunity cost of holding cash, it is optimal to start a holding period with some cash and spend it gradually until the next transfer, which initiates a new holding period. As a result, firms engage in $(S, s)$ policies on bonds and cash. The aggregate variables are obtained by the aggregation of these 
$(S, s)$ policies across firms. For constant inflation and interest rate, the $(S, s)$ policies of the firms in each group have the same pattern. The relevant variable for the firm is its position in the holding period. Let $n_{i} \in\left[0, N_{i}\right)$ denote the position of a firm of the group $i$ in the holding period. Firm $n_{i}$ makes transfers from the brokerage account to the bank account at $T_{1, i}\left(n_{i}\right)=n_{i}, T_{2, i}\left(n_{i}\right)=n_{i}+N_{i}$ and so on.

Consider the pattern of transactions for each firm. The first order condition for $c_{i}\left(t, n_{i}\right)$ of the problem of maximizing (1) subject to (5) and (6) implies $P(t) c_{i}\left(t, n_{i}\right)=$ $e^{-\rho t} /\left[\lambda_{i}\left(n_{i}\right) Q\left(T_{j}\right)\right]$, for $t \in\left(T_{j, i}\left(n_{i}\right), T_{j+1, i}\left(n_{i}\right)\right), j \geq 1$, where $\lambda_{i}\left(n_{i}\right)$ is the Lagrange multiplier of (5). Let $c_{0 i}$ denote transactions at the beginning of a holding period for firms in group $i$. The transactions during the holding periods of the firms in group $i$ are given by $c_{i}\left(t, n_{i}\right)=c_{0 i} e^{(r-\pi-\rho) t} e^{-r\left(t-T_{j, i}\right)}$, for $j$ such that $t \in\left[T_{j, i}\left(n_{i}\right), T_{j+1, i}\left(n_{i}\right)\right)$. Integrating the transactions of all firms in group $i$, we get the aggregate transactions of group $i, C_{i}(t)=c_{0 i} e^{(r-\pi-\rho) t}\left(1-e^{-r N_{i}}\right) /\left(r N_{i}\right)$. In the steady state equilibrium, the nominal interest rate is equal to the inflation rate plus the real interest rate $\rho$, i.e. $r=\rho+\pi$, since in the steady state the aggregate transactions of firms in the same group are constant.

Transactions during holding periods must be equal to the cash generated by sales during the same holding period, $\int_{T_{j, i}}^{T_{j+1, i}} c_{i}\left(t, n_{i}\right) d t=\int_{T_{j, i}}^{T_{j+1, i}} Y_{i} d t$, where $T_{j+1, i}-T_{j, i}=$ $N_{i}$. Given $r=\rho+\pi$, then $c_{i}\left(t, n_{i}\right)=c_{0 i} e^{-r\left(t-T_{j, i}\right)}$. Substituting $c_{0 i} e^{-r\left(t-T_{j, i}\right)}$ in the previous equation yields the value of transactions at the beginning of a holding period, $c_{0, i}\left(1-e^{-r N_{i}}\right) /\left(r N_{i}\right)=Y_{i}$. As we will parameterize the model using data on the cash-sales ratio of firms, it is useful to characterize the variable transactions-sales ratio. Let $\hat{c}_{i} \equiv c_{i} / Y_{i}$ denote the transactions-sales ratio of firms in group $i$. We have

$$
\hat{c}_{0, i}(r) \frac{1-e^{-r N_{i}}}{r N_{i}}=1
$$


which determines $\hat{c}_{0, i}$, given $N_{i}$ and $r$. The transactions-sales ratios during $t \in$ $\left[T_{j, i}\left(n_{i}\right), T_{j+1, i}\left(n_{i}\right)\right)$ for firms in group $i$ are given by $\hat{c}_{i}\left(t, n_{i}\right)=\hat{c}_{0 i} e^{-r\left(t-T_{j, i}\right)}$.

Aggregate cash holdings are equal to $M(t)=\sum_{i} v_{i} \frac{1}{N_{i}} \int M_{i}\left(t, n_{i}\right) d n_{i}$, where $M_{i}\left(t, n_{i}\right)=\int_{t}^{T_{j+1, i}\left(n_{i}\right)} P(\tau) \times c_{i}\left(\tau, s_{i}\right) d \tau$, and the aggregate cash-sales ratio is $m=$ $M(t) /(P(t) Y)$, which is constant at the steady state since the aggregate cash holdings grow at the same rate as inflation. In the appendix, we show that the aggregate cash-sales ratio in this economy is given by

$$
m=\frac{1}{Y} \sum_{i=1}^{I} v_{i} \frac{c_{0, i}(r)}{\rho} e^{-r N_{i}}\left[\frac{e^{r N_{i}}-1}{r N_{i}}-\frac{e^{(r-\rho) N_{i}}-1}{(r-\rho) N_{i}}\right]
$$

The price level at time zero is equal to $P_{0}=M_{0} /(m Y)$, where $M_{0}$ denotes the money supply at time zero and $Y$ denotes aggregate sales.

The cash-sales ratios of the firms in group $i$ are given by $m_{i}\left(n_{i}\right)=M_{0, i}\left(n_{i}\right) \times$ $\left(P_{0} Y_{0, i}\right)^{-1}, n_{i} \in\left[0, N_{i}\right)$, where $M_{0, i}\left(n_{i}\right)$ is the initial cash holdings for each $n_{i} \in$ $\left[0, N_{i}\right)$. The $M_{0, i}\left(n_{i}\right)$ compatible with an equilibrium where $r$ and $\pi$ are constant is obtained by requiring that $M_{0, i}\left(n_{i}\right)$ is just enough to cover transactions from $t=0$ until the first transfer of firm $n_{i}$, at $T_{1, i}\left(n_{i}\right)=n_{i}$. The $M_{0, i}\left(n_{i}\right)$, for $n_{i} \in\left[0, N_{i}\right)$ and $i=1, \ldots, I-1$, are determined in the appendix. After dividing by $P_{0} Y_{i}$, we obtain the cash-sales ratio of firms $n_{i} \in\left[0, N_{i}\right)$

$$
m_{i}\left(n_{i}\right)=\frac{r N_{i} e^{-r N_{i}} n_{i} e^{r n_{i}}}{1-e^{-r N_{i}}} \frac{1-e^{-\rho n_{i}}}{\rho n_{i}} .
$$

The cash-sales ratios have a distribution with support $\left[0, m_{H_{i}}\right)$, where $m_{H_{i}}=$ $\lim _{n_{i} \rightarrow N_{i}} m\left(n_{i}\right)$. As firms are distributed uniformly along $\left[0, N_{i}\right)$, the density $f_{i}(x)$ of the firms' cash-sale ratios is given by $\frac{1}{N_{i}} \frac{\partial m_{i}^{-1}(x)}{\partial m}$, where $m_{i}^{-1}(x)$ is the value of $n_{i}$ such that $m_{i}\left(n_{i}\right)=x$. There exists a unique value of $m_{i}^{-1}(x)$, as $m_{i}\left(n_{i}\right)$ is 
strictly increasing. Therefore, $f_{i}(x)=\frac{1}{N_{i}}\left[r x+\frac{r N_{i}}{1-e^{-r N_{i}}} e^{-r N_{i}} e^{(r-\rho) m_{i}^{-1}(x)}\right]^{-1}, m_{i} \in$ $\left[0, m_{H_{i}}\right)$. For the aggregate firms in the economy, the density function is $f(x)=$ $\sum_{i} v_{i} f_{i}(x) d x$, where $v_{i}$ is the fraction of firms distributed along $\left[0, N_{i}\right)$, which ensures that $\int f(x) d x=1$. Thus, in an economy with constant $r$ and $\pi$, at any moment in time the cross section of the cash-sales ratio will be given by $f(x), x \in\left[0, \max \left(m_{H_{i}}\right)\right)$.

In the data, the distribution of real money holdings is concentrated on small quantities of money, but it can be approximated by a weighted combination of uniform distributions. In the parameterization, the values of $v_{i}$ and $m_{H_{i}}$ are set so that the model distribution of the cash-sales ratio approximates the actual distribution available in the Compustat data. Figure 6 shows an example with $I=4$.

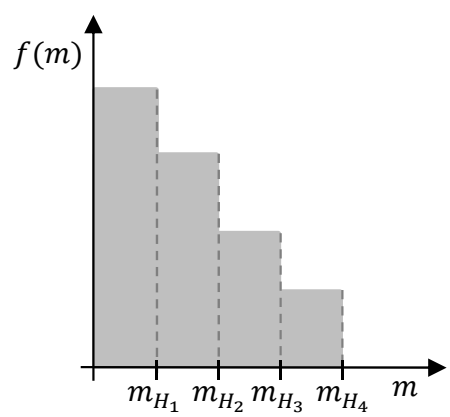

FIG. 6: The parameterization is made by finding the values of $m_{H_{i}}$ and $v_{i}, i=1, \ldots, I$, so that the model distribution of cash-sales ratios approximates the distribution in the data. $I$ is set to 50 in the simulations.

Figure 7 shows the actual distribution and the parameterized distributions for the years 1980 and 2010. The actual distributions in the figure are the same as the ones shown in figure 5 for 1980 and 2010. For each year, the nominal interest rate, $r$, is the commercial paper interest rate and the values of $m_{H_{i}}$ and $v_{i}$ are found to match the actual distributions of the cash-sales ratios. As explained in the next section, instead of $v_{i}$, we use the fraction of sales of firms in group $i$ with respect to total 
sales, $v_{Y_{i}}$, to obtain a counterpart with the data on cash-sales. ${ }^{13}$ Figure 7 shows the logs of the cash-sales ratio, as the distribution of the levels is highly asymmetric toward small values of the cash-sales ratio.
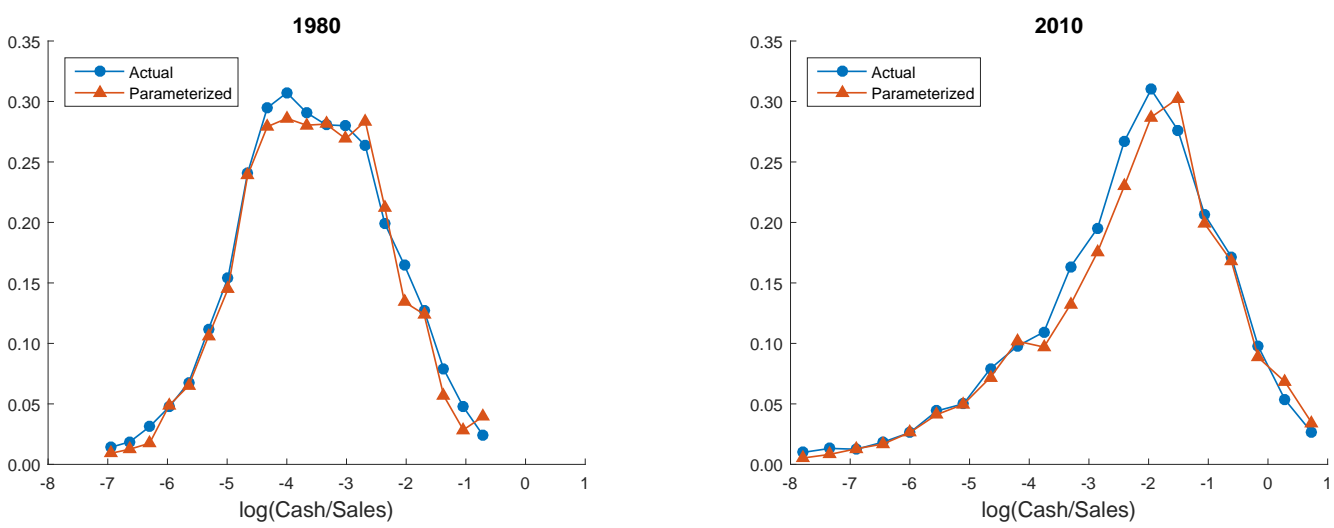

FIG. 7: Actual distribution and parameterization for 1980 and 2010 of the cash-sales ratio.

\section{Firm Cash Holdings and Monetary Policy Shocks}

The monetary policy is summarized by the nominal interest rate path $r(t), t \geq 0$. Since a change in $r(t)$ affects firm $i$ 's cash holdings $M_{i}\left(t, n_{i}\right)$, when setting the interest rate path, the central bank has to adjust the money supply accordingly. The central bank supplies $M(t)$ to satisfy the market clearing condition for cash. The interest rate path determines bond prices $Q(t)=e^{-R(t)}$, where $R(t)=\int_{0}^{t} r(s) d s$.

In the model, it is equivalent to set $M(t)$ and obtain the equilibrium $r(t)$ or to set $r(t)$ and obtain the equilibrium $M(t)$. However, it is computationally simpler to set $r(t)$ to obtain the equilibrium prices through the relevant equilibrium equations. Moreover, the evidence suggests that the practice of central banks is to set monetary

\footnotetext{
${ }^{13} v_{i}=\frac{n_{i}}{\sum n_{i}}$ whereas $v_{Y_{i}}=\frac{n_{i} Y_{i}}{Y}$. Both $\sum v_{i}=\sum v_{Y_{i}}=1$. We have that $v_{Y_{i}}=\frac{Y_{i}}{Y} v_{i}$, where $\bar{Y}=\frac{Y}{\sum n_{i}}$. The advantage of using $v_{Y_{i}}$ is that it allows the characterization of the equilibrium variables with the expression for the consumption-income ratio.
} 
policy through the interest rate. By focusing on $r(t)$ as the target for the monetary policy, we follow the literature, for example, Woodford (2003).

Let $t=0$ be the time of the interest rate shock. When the unexpected change in the interest rate hits the economy firms have different cash holdings. Firms with little cash are about to make a transfer. These firms adapt faster to the shock because they will make a transfer soon after the shock. Firms with large cash holdings take longer to make their transfer. They can only adjust transactions until the moment they make the transfer. ${ }^{14}$

The different reactions of the firms with respect to transactions and transfers affect the real interest rate. The gradual reactions of the firms, after an increase in the nominal interest rate, make the price level move slower than if there was no market segmentation. Thus, as the real interest rate is equal to the difference between the nominal interest rate and the rate of inflation, the real interest rate increases together with the nominal interest rate just after a positive shock. ${ }^{15}$

Let $\operatorname{rr}(t)$ denote the real interest rate and $\pi(t)$ denote the rate of inflation, $\pi(t) \equiv$ $\dot{P}(t) / P(t)$. The real interest rate at each moment is given by $r r(t)=r(t)-\pi(t)$, for $t \geq 0$. To obtain $\operatorname{rr}(t)$, we have to determine the price level at each time $P(t)$. The shock occurs when the economy is in a steady state with constant interest rate $r$ and constant inflation $\pi$. Before the shock, the real interest rate is $\rho$ and $r=\rho+\pi$. Cash and bond holdings of firm $i$ at the time of the shock, $M_{0, i}\left(n_{i}\right)$ and $B_{0, i}\left(n_{i}\right)$, are the steady state values corresponding to the nominal interest rate $r$. These cash holdings represent the choices before the shock. As Grossman (1987), we assume that

\footnotetext{
${ }^{14}$ Christiano, et al. (1996) present evidence that firms take some time to adjust their portfolios after an interest rate shock. Adjustments are not instantaneous.

${ }^{15} \mathrm{~A}$ slow response of prices and an increase in the real interest rate after an increase in the nominal interest rate is found in many empirical studies. Among others, Cochrane (1994), Christiano et al. (1999), Khan et al. (2002), Bernanke et al. (2005), and Uhlig (2005).
} 
bonds $B_{0, i}\left(n_{i}\right)$ are contingent to the shock, but cash is not. According to Grossman (1987) the problem of the entrepreneur needs to be extended to two states of nature. In one state of nature, the economy continues in the steady state and in the other state of nature the nominal interest rate follows $r(t)$. This problem is stated and solved formally in the appendix.

The equilibrium price level is obtained through the market clearing condition for goods. At time $t$, not long after the shock, there will be firms in each group $i$ that have made a transfer already, and other firms that have not made a transfer yet after the shock. Firms that have not made the transfer yet, must do transactions using what is left out of $M_{0, i}\left(n_{i}\right)$. Firms that have made the transfer already, are firms with smaller values of $n_{i} \in\left[0, N_{i}\right)$, as they make the first transfer at $T_{1, i}=n_{i}$. Aggregate transactions for all firms in group $i$ are given by

$$
C_{i}(t)=\frac{1}{N_{i}} \int_{0}^{t} \frac{e^{-\rho t}}{\lambda_{i}\left(n_{i}\right) Q\left(T_{1, i}\left(n_{i}\right)\right) P(t)} d n_{i}+\frac{1}{N_{i}} \int_{t}^{N_{i}} \frac{e^{-\rho t}}{\mu_{i}\left(n_{i}\right) P(t)} d n_{i}, 0 \leq t<N_{i}
$$

where $\lambda_{i}\left(n_{i}\right)=1 /\left(P_{0} c_{0, i}\left(n_{i}\right)\right)$ is the Lagrange multiplier associated with the intertemporal budget constraint and $\mu_{i}\left(n_{i}\right)$ is the Lagrange multiplier associated with the cash in advance constraint of the first period; the value of $\mu_{i}\left(n_{i}\right)$ depends on $M_{0, i}\left(n_{i}\right)$ and it is determined in the appendix. The second term in the right of equation (11) explains most of the transactions when $t$ is close to zero; and the first term determines most of the transactions when $t$ is close to $N_{i}$. The interpretation is that when most firms have not yet reacted to the shock, i.e. $t$ is close to zero, the value of $\mu\left(n_{i}\right)$ is important to determine consumption and ultimately to determine prices.

The equilibrium price path $P(t)$ is obtained by equating aggregate demand, $\sum v_{i}$ $\times C_{i}(t)$, to aggregate sales, $Y$. The logarithm utility allows us to isolate $P(t)$. In order to obtain a counterpart with the data on cash-sales, we rewrite the equation 
in terms of the fraction of sales of firms in group $i$ with respect to total sales, which we denote by $v_{Y_{i}}$. Proposition 1 describes the solution for prices obtained with equation (11). The version of the market segmentation model that we use gives us great flexibility. Apart from the integral in $e^{R(n)}$, which can be solved easily with numerical methods, we have closed-form solutions for the price level for any $r(t) .{ }^{16}$

Proposition 1 Prices after shocks. The equilibrium price level $P(t)$ after a nominal interest rate shock with path $r(t), t \geq 0$, is given by

$$
\begin{aligned}
P(t) & =\sum_{i=1}^{I} v_{Y_{i}} \frac{P_{0}}{N_{i}} \hat{c}_{0, i} e^{-\rho t}\left[\int_{0}^{t} e^{R\left(n_{i}\right)} d n_{i}+\frac{1-e^{-r\left(N_{i}-t\right)}}{r N_{i}}\right], \text { for } 0 \leq t<N_{1}, \\
P(t) & =v_{Y_{1}} \frac{P_{0}}{N_{1}} \hat{c}_{0,1} e^{-\rho t} \int_{t-N_{1}}^{t} e^{R\left(n_{1}\right)} d n_{1} \\
+ & \sum_{i=2}^{I} v_{Y_{i}} \frac{P_{0}}{N_{i}} \hat{c}_{0, i} e^{-\rho t}\left[\int_{0}^{t} e^{R\left(n_{i}\right)} d n_{i}+\frac{1-e^{-r\left(N_{i}-t\right)}}{r N_{i}}\right], \text { for } N_{1} \leq t<N_{2}, \\
\vdots & \\
P(t) & =\sum_{i=1}^{I} v_{Y_{i}} \frac{P_{0}}{N_{i}} \hat{c}_{0, i} e^{-\rho t} \int_{t-N_{i}}^{t} e^{R\left(n_{i}\right)} d n_{i}, \text { for } t \geq N_{I},
\end{aligned}
$$

where $R\left(n_{i}\right) \equiv \int_{0}^{n_{i}} r(s) d s$.

As $M_{0, i}\left(n_{i}\right)$ are cash holdings in the initial steady state, they can be too large for the new interest rate path $r(t)$. After the shock firms may choose, to make a transfer before their stock of money vanishes, i.e. $M_{i}^{-}\left(T_{1, i}\left(n_{i}\right), n_{i}\right)>0$. In the proof of proposition 1 , we show that will not happen, i.e. $M_{i}^{-}\left(T_{1, i}\left(n_{i}\right), n_{i}\right)=0$ for any $r(t)$. When there is a shock, firms adapt to the shock by changing transactions rather than choosing $M_{i}^{-}\left(T_{1, i}\left(n_{i}\right), n_{i}\right)>0$.

Proposition 1 implies that monetary policy affects real interest rates. According to the Fisher relation $r r(t)=r(t)-\pi(t)$, the real interest rate changes after a nominal

\footnotetext{
${ }^{16}$ In particular, we don't need to assume an arbitrary initial path for the price level $P^{0}(t)$, $t \in[0,+\infty)$, and iterate $P^{j}(t)$ until it converges. That would greatly slow down the solution. The assumption of logarithmic preferences allows us to isolate $P(t)$.
} 
interest rate shock if inflation moves slowly after the shock. In a standard cash-inadvance model, $\pi(t)$ changes instantaneously after a shock to $r(t)$ and $r r(t)$ remains constant. Here, $\pi(t)$ remains constant just after the shock and changes gradually because of the market segmentation. As a result, the real interest rate increases with the increase in the nominal interest rate.

We can determine the effects of market segmentation using (12). Suppose, for example, that the shock is a permanent increase of the nominal interest rate from $r_{1}$ to $r_{2}$. Before the shock, inflation is equal to $r_{1}-\rho$ and the real interest rate is equal to $\rho$. We have $e^{R(t)}=e^{r_{2} t}$. Solving for $\dot{P}(t) / P(t)$, we obtain that inflation just after the shock is equal to $r_{1}-\rho$, its value before the shock, and the real interest rate increases to $\rho+r_{2}-r_{1}$. For $t \geq \max \left(N_{i}\right)=N_{I}$, we have $P(t)=k e^{\left(r_{2}-\rho\right) t}$, where $k$ is a positive constant. Only after $N_{I}$, when all firms have made their first bond trade after the shock, does inflation increase to $r_{2}-\rho$. If $N_{I}$ is a large number, it will take longer for inflation to converge to its value at the new steady state and the effects on the real interest rate will be more prolonged. A nominal shock, however, cannot affect real variables indefinitely. As time goes by, the real interest decreases gradually to its steady state value, $\rho$.

Proposition 2 establishes these two results: just after the shock the real interest rate increases by the same amount as the nominal interest rate and the real interest rate does not move if we eliminate market segmentation.

Proposition 2 Slow reaction of prices. For any interest rate path $r(t)$ announced at time $t=0$, the price level and the inflation rate do not move just after the shock, that is, $P(0)=P_{0}, \pi(0)=r-\rho$. Moreover, the change in the real interest rate at $t=0$ is equal to the change in the nominal interest rate, $r r(0)-\rho=r(0)-r$. If $N_{i} \rightarrow 0$, for all $i=1, \ldots, I$, the real interest rate is constant and equal to $\rho$ for 
any $r(t)$ and all $t \geq 0$.

Consider now a monetary policy shock as the one estimated by Uhlig (2005). According to figure 2, plot 6, in Uhlig, reproduced in figure 8, a monetary policy shock, described as an increase in the federal funds rate, initially increases the interest rate 0.3 percentage points and gradually decreases the interest rate towards its initial value. On average, the interest rate returns to its initial value in about 2 years and stays below its initial value for some time until it returns to zero. We approximate this shock with the process for the interest rate given by $r(t)=r_{1}+\left(r_{2}-r_{1}+B t\right) e^{-\eta t}$, also depicted in figure 8 , where $r_{2}-r_{1}=0.3$ percentage points per year. We set $B$ and $\eta$ so that $r(t)$ approximates the average impulse response of the federal funds rate as estimated by Uhlig (2005). We set $\rho=3$ percent per year. ${ }^{17}$ The estimation in figure 8, as explained by Uhlig, uses a range of OLS estimates of a VAR. We later use different estimates for the monetary policy shock for comparison. ${ }^{18}$

Given the distributions of the cash-sales ratio from 1980 to 2013, we hit the economy with the shock $r(t)$ and obtain the real interest rate path using the expressions of proposition 1. As explained in section 4, the cash-sales distribution for each year is obtained by determining the values of $v_{Y_{i}}$ and $N_{i}$ so that the distribution of the cash-sales ratio from the model approximates the actual distribution of the cash-sales ratio given by Compustat data. ${ }^{19}$ According to proposition 1, the real interest rate $r r(t)$ implied by the shock to $r(t)$ depends on the distribution of the cash-sales ratio

\footnotetext{
${ }^{17}$ This value for $\rho$ has been used by Lucas (2000), Silva (2012), among others. It implies that a nominal interest rate of 3 percent per year in the steady state generates zero inflation.

${ }^{18}$ The expression of $r(t)$ is the result of the differential equation $m \ddot{r}(t)+c \dot{r}(t)+k r(t)=0$, $\eta=c /(2 m)$, which describes a dampened shock. We set $r_{1}=3 \%$ p.a. and $r_{2}=3.3 \%$ p.a. Figure 8 expresses the results as the difference from the initial value of the nominal interest rate. In our simulations, $t$ denotes one day and we divide the year in 360 days. $B=-0.15 \%$ and $\eta=0.30$, for $r(t)$ given in percentage per year.

${ }^{19}$ Table A.1 in the appendix shows the values of $v_{Y i}$ and $N_{i}$ for 1980 and 2010.
} 


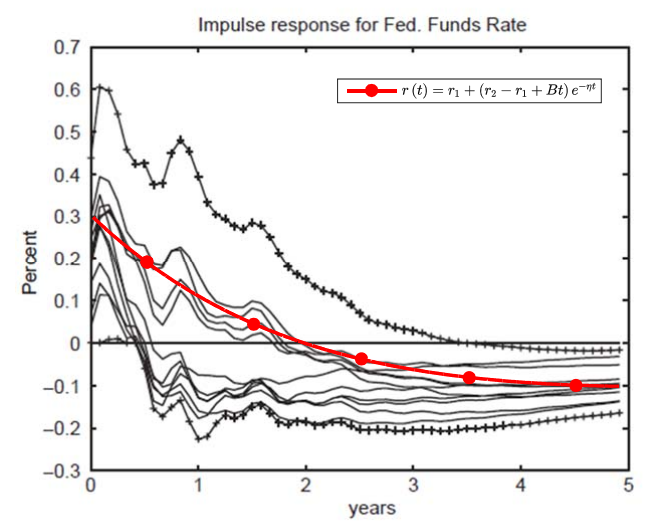

FIG. 8: Process for the nominal interest rate path, $r(t)=r_{1}+\left(r_{2}-r_{1}+B t\right) e^{-\eta t}$, with the parameters $B$ and $\eta$ used in the simulations, $B=-0.15 \%$ and $\eta=0.30$, for $r(t)$ given in percentage per year. The parameters $B$ and $\eta$ were chosen to approximate the impulseresponse function for the monetary policy shock estimated in Uhlig. Figure reproduced from Uhlig (2005), Fig 2, plot 6), with the process $r(t)$ for the nominal interest rate path added to the figure.

across firms. The paths for the real interest rates for each year are our predicted effects of shocks to $r(t)$ given the distributions of the cash-sales ratio.

Figure 9 shows the equilibrium real interest rate obtained from the model for the cash-sales distributions of the selected years from 1980 to 2013 as shown in figure 5. We show the difference in percentage points from the initial value of the real interest rate. For a standard cash-in-advance model, we would have a straight line after the shock, $\operatorname{rr}(t)=0$, as a standard cash-in-advance model implies an instantaneous reaction of prices and no change in real interest rates. Here, with market segmentation, the real interest rate increases after the nominal interest rate shock and returns gradually to its initial value.

We measure the effect of monetary policy by the time that it takes for the real interest rate to reach its initial value. In figure 9 , we have, for example, that the real interest rate reaches its initial value in 1.84 month given the cash distribution of 1980. Given the cash distribution of 2013, the real interest rate reaches its initial 


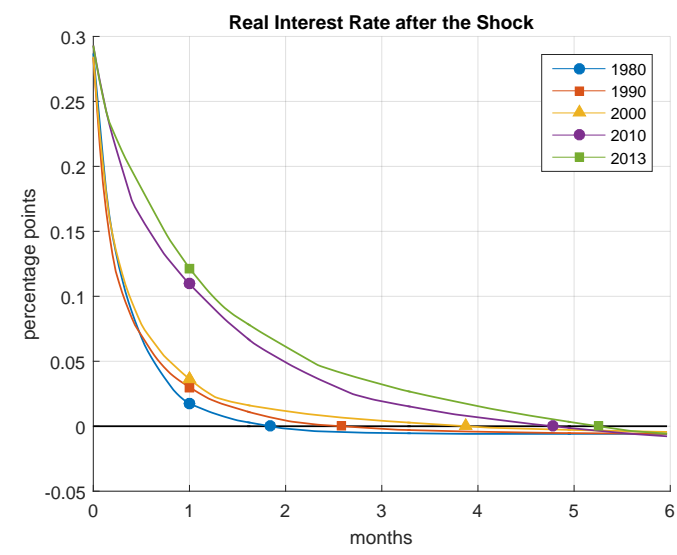

FIG. 9: Response of the real interest rate for selected years given the nominal interest rate shock of figure (8). Results from simulations. The distribution of cash holdings is determined with data for each year. The markers in the horizontal axis show the time for the real interest rate to return to its initial value. The values are $1.84,2.58,3.88,4.78$, and 5.25 months for the selected years. The values for all years are in figure (1).

value in 5.25 months. The values for all years from 1980 to 2013 obtained through the simulations are in figure 1.

The effect on the real interest rate implied by the model changes as the distribution of cash-sales ratio changes from 1980 to 2013. The recent distribution of cash-sales makes the real interest rate take longer to return to its initial value. The monetary authority, therefore, is able to affect the real interest for a longer period.

To check the robustness of our results, we simulate the economy with different paths for the monetary policy shock and with different cash aggregates. We use other identification methods of the shock, recalculate the parameters $B$ and $\eta$ of the process for $r(t)$, and obtain the effect of the shock for the different estimates.

Besides using different identification methods for the monetary policy shock, we verify our results with different cash aggregates. Our results in figure 1 use cash and equivalents $(\mathrm{CHE})$ for the distribution of cash across firms, as $\mathrm{CHE}$ is the variable 
usually used for firm cash holdings. ${ }^{20}$ It may be argued, however, that CHE contains variables that are not in traditional monetary aggregates such as short-term marketable security, which is part of CHE but not of M1. ${ }^{21}$ To check whether we maintain our results with a more restricted variable for firm cash holdings, we repeat the exercise using only the cash component of cash and equivalents ( $\mathrm{CH}$ instead of CHE).

We use three forms of identification of the monetary policy shock, provided by Uhlig (2005). In the first, used to obtain the results of figure 1, Uhlig generates impulse-response functions, obtained from an OLS estimate of a VAR, that satisfies sign restrictions for the monetary policy shock and the price level for six months after the shock. Figure 8, reproduced from Fig 2 of Uhlig (2005), contains the results of this identification exercise. The figure has ten random draws of the impulse responses that satisfy the sign restrictions and the upper and lower bounds of ten thousand random draws of impulse responses. We added the process $r(t)$ used in our simulations, with the parameters $B$ and $\eta$ chosen to approximate the impulse-response function of the shock.

The second method of identification follows a conventional identification procedure found, for example, in Christiano et al. (1999). This method uses a standard Cholesky decomposition and there is no imposition of sign restrictions. The third method, called pure-sign-restriction approach by Uhlig, also imposes sign restrictions for the identification and uses Bayesian methods. The OLS estimate and the pure-

\footnotetext{
${ }^{20}$ Cash and equivalents is used, for example, by Almeida, Campello, and Weisbach (2004), Bover and Watson (2005), Bates, Kahle and Stultz (2009), Bacchetta, Benhima, and Poilly (2014), among others.

${ }^{21}$ A substantial part of CHE, in any case, is comprised by cash, which, by the industrial definition, "represents any immediately negotiable medium of exchange or any instruments normally accepted by banks for deposit and immediate credit to a customer's account" (Compustat). This definition closely resembles the definition of M1.
} 
sign-restriction approach produce similar results, although the pure-sign-restriction approach satisfies additional technical requirements. The conventional identification implies a larger increase of the interest rate at the time of the shock and a more persistent shock as compared with the OLS estimate. The pure-sign-restriction approach implies a smaller shock at the time of the shock and a somewhat more persistent shock. The shock identified with the OLS estimate is in between the pure-signrestriction approach and the conventional identification. ${ }^{22}$

With the three different identification methods for the monetary policy shock and the two variables for cash holdings, we have a total of six different simulations. The results of these simulations are in figure 10. For comparison, the results in figure 1 are repeated in the first plot of figure 10 for the case with CHE.

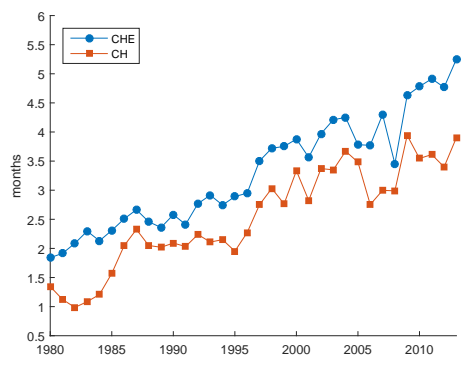

(a) OLS estimate

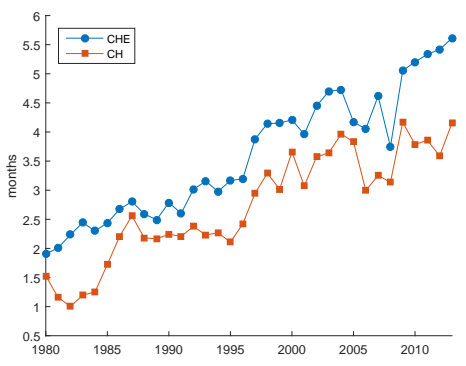

(b) Conventional identification

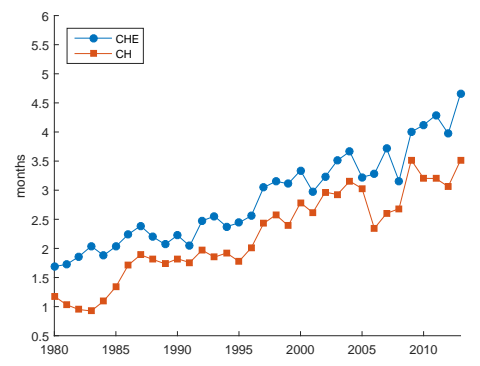

(c) Pure-sign-restriction approach

FIG. 10: Robustness check. Months to return to the initial interest rate with different identification methods for $r(t)$ and different cash aggregates. Different estimates for $r(t)$ from Uhlig (2005). OLS estimate: VAR with sign restrictions obtained by OLS and random draws of possible impulse-response functions. Conventional identification: conventional VAR without sign restrictions. Pure-sign-restriction approach: VAR with sign restrictions obtained with Bayesian methods. CHE: simulations with cash and equivalents. CH: simulations with the cash portion of cash and equivalents. The results in figure (1) are repeated in the first plot with CHE. For all cases, the time to return to the initial value of the real interest rate increases substantially.

\footnotetext{
${ }^{22}$ For the OLS estimate, conventional identification, and pure-sign-restriction approach: $B=$ $-0.150, \eta=0.3008 ; B=-0.158, \eta=0.4497$; and $B=-0.167, \eta=0.3852$.
} 
All simulations imply that the time that it takes for the real interest rate to return to its initial value increases as we change the cross-sectional distribution of cash holdings from 1980 to 2013. The pure-sign-restriction approach implies a smaller monetary policy shock. As a result, the simulations yield smaller effects on the real interest rate. The time during which the real interest rate is above its initial value increases from 1.7 month in 1980 to 4.6 months in 2013, using the CHE aggregate, compared with an increase from 1.8 month to 5.3 months with the OLS estimate. The increase in cash holdings would therefore imply an increase on the effects of the real interest rate of 2.9 months according with the pure-sign-restriction and 3.5 according with the OLS estimate. On the other hand, the conventional identification method for the monetary policy shock implies a larger shock and a more persistent interest rate shock. The simulations then yield longer effects on the real interest rate. They also yield a larger difference between the duration in 1980 and 2013. The real interest rate takes 1.9 month in 1980 and 5.6 months in 2013 to return to its initial value. The effect of the increase in cash holdings is then 3.7 months with the conventional identification.

The use of $\mathrm{CH}$ instead of $\mathrm{CHE}$ for the cash aggregate, also implies a more prolonged effect of monetary policy under the cash distribution of recent periods. CHE implies larger effects of monetary policy, although the effects in percentage terms are larger with $\mathrm{CH}$. The predictions about the large increase in the time for the real interest rate to return to its initial value are valid for both $\mathrm{CH}$ and $\mathrm{CHE}$. The difference of the time for the real interest rate to return to its initial value is less than 1 month on average for the simulations made with either $\mathrm{CH}$ or with $\mathrm{CHE} .{ }^{23}$

\footnotetext{
${ }^{23}$ We also used different ways of treating the data, using different constraints on minimum cash holdings, truncation values for the cash-sales ratio, and minimum sales. These modifications do not change conclusions in a significant way.
} 
Our simulations have the objective of isolating the effect of the changes in the level of cash holdings and in the cross-sectional distribution of cash holdings from 1980 to 2013. Our point is that the increase from 1.9 month in 1980 to 5.6 month in 2013 can be attributed, according to our simulations, to the changes the behavior toward cash holdings over the period. The model used by us, with market segmentation and a non-degenerate distribution of cash holdings, is particularly useful to obtain these predictions.

The exercises with alternative calibration methods, different interest rate shocks and different cash aggregates shocks, summarized in figure 10, show that our predictions are not sensitive to changes around the setup of our first results. We still find that the recent changes in the distribution of cash holdings generates a longer period during which the real interest rate is affected by monetary policy. The conclusion that the current distribution of firm cash holdings implies stronger effects of monetary policy shocks is a robust finding.

\section{Conclusions}

We show that the increase in cash holdings by firms has strong macroeconomic consequences. We find that it affects the response of the real interest rate to nominal interest rate shocks. The effect of firm cash holdings on monetary policy is substantial. According to our predictions, the changes in the distribution of cash holdings from 1980 to 2013 imply that the real interest rates takes 3.4 months more in 2013 than in 1980 to return to its initial value after a shock.

The current distribution of cash holdings implies that changes in monetary policy have more prolonged effects. There is a current debate about how central banks should increase nominal interest rates back to normal values, when the effects of the 
financial crisis and of the sovereign debt crisis are mitigated. An implication of our results is that these changes in interest rates should be made gradually. Given the high current values of the cash-sales distribution as compared to past values, changes in nominal interest rates will imply stronger effects in the economy.

\section{References}

Acharya, Viral A., Heitor Almeida, and Murillo Campello (2007). "Is Cash Negative Debt? A Hedging Perspective on Corporate Financial Policies." Journal of Financial Intermediation 16, 515-554.

Adao, Bernardino, and Andre C. Silva (2015). "Financial Frictions and Interest Rate Shocks."

Almeida, Heitor, Murillo Campello, and Michael S. Weisbach (2004). "The Cash Flow Sensitivity of Cash." Journal of Finance 59, 1777-1804.

Alvarez, Fernando, Andrew Atkeson, and Chris Edmond (2009). "Sluggish Responses of Prices and Inflation to Monetary Shocks in an Inventory Model of Money Demand." Quarterly Journal of Economics 124(3): 911-967.

Alvarez, Fernando, and Francesco Lippi (2009). "Financial Innovation and the Transactions Demand for Cash." Econometrica 77(2): 363-402.

Bacchetta, Philippe, Kenza Benhima, and Celine Poilly (2014). "Corporate Cash and Employment."

Bacchetta, Philippe, and Eric van Wincoop (2010). "Infrequent Portfolio Decisions: A Solution to the Forward Discount Puzzle." American Economic Review 100(3): 870-904.

Bachmann, Rudiger, and Lin Ma (2016). "Lumpy Investment, Lumpy Inventories." Journal of Money, Credit and Banking 48(5): 821-855.

Bates, Thomas W., Kathleen M. Kahle, and Rene M. Stulz (2009). "Why Do U.S. Firms Hold so Much More Cash than They Used to?" Journal of Finance 64(5): 1985-2021.

Baumol, William J. (1952). "The Transactions Demand for Cash: An Inventory Theoretic Approach." Quarterly Journal of Economics 66(4): 545-556.

Bernanke, Ben S., Jean Boivin, and Piotr Eliasz (2005). "Measuring the Effects of Monetary Policy: a Factor-Augmented Vector Autoregressive (FAVAR) Approach." Quarterly Journal of Economics 120(1): 387-422.

Blanchard, Olivier J., Florencio Lopez-de-Silanes, and Andrei Shleifer (1994). "What do Firms Do with Cash Windfalls?" Journal of Financial Economics 36: 337-360. 
Bolton, Patrick, and Xavier Freixas (2006). "Corporate Finance and the Monetary Transmission Mechanism." Review of Financial Studies 19(3): 829-870.

Bover, Olympia, and Nadine Watson (2005). "Are There Economies of Scale in the Demand for Money by Firms? Some Panel Data Estimates." Journal of Monetary Economics 52(8): 1569-1589.

Carvalho, Carlos, and Fernanda Nechio (2011). "Aggregation and the PPP Puzzle in a Sticky-Price Model." American Economic Review 101(6): 2391-2424.

Chari, V.V., Patrick J. Kehoe, and Ellen R. McGrattan (2008). "Are Structural VARs with Long-Run Restrictions Useful in Developing Business Cycle Theory?" Journal of Monetary Economics 55(8): 1337-1352.

Christiano, Lawrence J., Martin Eichenbaum, and Charles Evans (1996). "The Effects of Monetary Policy Shocks: Evidence from the Flow of Funds." Review of Economics and Statistics 78(1): 16-34.

Christiano, Lawrence J., Martin Eichenbaum, and Charles Evans (1999). "Monetary Policy Shocks: What Have We Learned and to What End?" Handbook of Macroeconomics, Michael Woodford and John Taylor (eds.). Amsterdam: North Holland.

Christiano, Lawrence J., Martin Eichenbaum, and Charles Evans (2005). "Nominal Rigidities and the Dynamic Effects of a Shock to Monetary Policy." Journal of Political Economy 113(1): 1-45.

Clarida, Richard, Jordi Gali, and Mark Gertler (1999). "The Science of Monetary Policy: A New Keynesian Perspective." Journal of Economic Literature 37(4): 1661-1707.

Clarida, Richard, Jordi Gali, and Mark Gertler (2000). "Monetary Policy Rules and Macroeconomic Stability: Evidence and Some Theory." Quarterly Journal of Economics 115(1): 147-180.

Cochrane, John H. (1994). "Shocks." Carnegie-Rochester Conference Series on Public Policy 41: 295-364.

Cole, Harold, and Lee E. Ohanian (2002). "Shrinking Money: The Demand for Money and the Nonneutrality of Money." Journal of Monetary Economics 49(4): 653-686.

Dittmar, Amy, and Jan Mahrt-Smith (2007). "Corporate Governance and the Value of Cash Holdings." Journal of Financial Economics 83: 599-634.

Dittmar, Amy, Jan Mahrt-Smith, and Henri Servaes (2003). "International Corporate Governance and Corporate Cash Holdings." Journal of Financial and Quantitative Analysis 38(1): 111-133.

Foley, C. Fritz, Jay Hartzell, Sheridan Titman, and Garry J. Twite (2007). "Why Do Firms Hold So Much Cash? A Tax-Based Explanation." Journal of 
Financial Economics 86: 579-607.

Frenkel, Jacob A., and Boyan Jovanovic (1980). "On Transactions and Precautionary Demand for Money." Quarterly Journal of Economics 95(1): 25-43.

Fresard, Laurent (2010). "Financial Strength and Product Market Behavior: The Real Effects of Corporate Cash Holdings." Journal of Finance 65(3): 1097-1122.

Golosov, Michael, and Robert Lucas (2007). "Menu Costs and Phillips Curves." Journal of Political Economy 115(2): 171-199.

Grossman, Sanford J. (1987). "Monetary Dynamics with Proportional Transaction Costs and Fixed Payment Periods." In New Approaches to Monetary Economics, ed. William A. Barnett and Kenneth J. Singleton, 3-41. Cambridge, UK: Cambridge University Press.

Grossman, Sanford J., and Laurence Weiss (1983). "A Transactions-Based Model of the Monetary Transmission Mechanism." American Economic Review 73(5): 871-880.

Harford, Jarrad (1999). "Corporate Cash Reserves and Acquisitions." Journal of Finance 54(6): 1969-1997.

Harford, Jarrad, Sattar, and Maxwell (2008). "Corporate Governance and Firm Cash Holdings in the U.S." Journal of Financial Economics 87: 535-555.

Jensen, Michael (1986). "Agency Costs of Free Cash Flow, Corporate Finance and Takeovers." American Economic Review 76(2): 323-329.

Kahn, Michael, Shmuel Kandel, Oded Sarig (2002). "Real and Nominal Effects of Central Bank Monetary Policy." Journal of Monetary Economics 49(8): 1493-1519.

Kalcheva, Ivalina and Karl V. Lins (2007). "International Evidence on Cash Holdings and Expected Managerial Agency Problems." Review of Financial Studies 20(4): 1087-1112.

Kashyap, Anil K., and Jeremy C. Stein (2000). "What Do a Million Observations on Banks Say About the Transmission of Monetary Policy?" American Economic Review 90(3): 407-428.

Kim, Chang-Soo, David C. Mauer, and Ann E. Sherman (1998). "The Determinants of Corporate Liquidity: Theory and Evidence." Journal of Financial and Quantitative Analysis 33: 335-359.

Lucas, Robert E., Jr., and Nancy L. Stokey(1987). "Money and Interest in a Cash-in-Advance Economy." Econometrica 55(3): 491-513.

Mankiw, N. Gregory, and Ricardo Reis (2002). "Sticky Information versus Sticky Prices: A Proposal to Replace the New Keynesian Phillips Curve." Quarterly Journal of Economics 117(4): 1295-1328.

Mulligan, Casey (1997). "Scale Economies, the Value of Time, and the Demand 
for Money: Longitudinal Evidence from Firms." Journal of Political Economy 105(5): 1061-1079.

Miller, Merton H., and Daniel Orr (1966). "A Model of the Demand for Money by Firms." Quarterly Journal of Economics 80(3): 413-435.

Palazzo, Berardino (2012). "Cash Holdings, Risk, and Expected Returns." Journal of Financial Economics 104(1): 162-185.

Pinkowitz, Lee, Rene Stulz, and Rohan Williamson (2006). "Does the Contribution of Corporate Cash Holdings and Dividends to Firm Value Depend on Governance? A Cross-country Analysis." Journal of Finance 61(6): 2725-2751.

Opler, Tim, Lee Pinkowitz, René M. Stulz, and Rohan Williamson (1999). "The Determinants and Implications of Corporate Cash Holdings." Journal of Financial Economics 52: 3-46.

Ozkan, Aydin, and Neslihan Ozkan (2004). "Corporate Cash Holdings: An Empirical Investigation of UK Companies." Journal of Banking and Finance 28: 2103-2134.

Rotemberg, Julio J. (1984). "A Monetary Equilibrium Model with Transactions Costs." Journal of Political Economy 92(1): 40-58.

Silva, Andre C. (2012). "Rebalancing Frequency and the Welfare Cost of Inflation." American Economic Journal: Macroeconomics 4(2): 153-183.

Stein, Jeremy C. (1998). "An Adverse-Selection Model of Bank Asset and Liability Management with Implications for the Transmission of Monetary Policy." Rand Journal of Economics 29(3): 466-486.

Tobin, James (1956) "The Interest-Elasticity of Transactions Demand for Cash." Review of Economics and Statistics 38(3): 241-247.

Uhlig, Harald (2005). "What Are the Effects of Monetary Policy on Output? Results from an Agnostic Identification Procedure." Journal of Monetary Economics 52(2): 381-419.

Woodford, Michael (2003). Interest and Prices. Princeton University Press: Princeton.

Yun, Hayong (2009). "The Choice of Corporate Liquidity and Corporate Governance." Review of Financial Studies 22(4): 1447-1475. 


\section{Appendix}
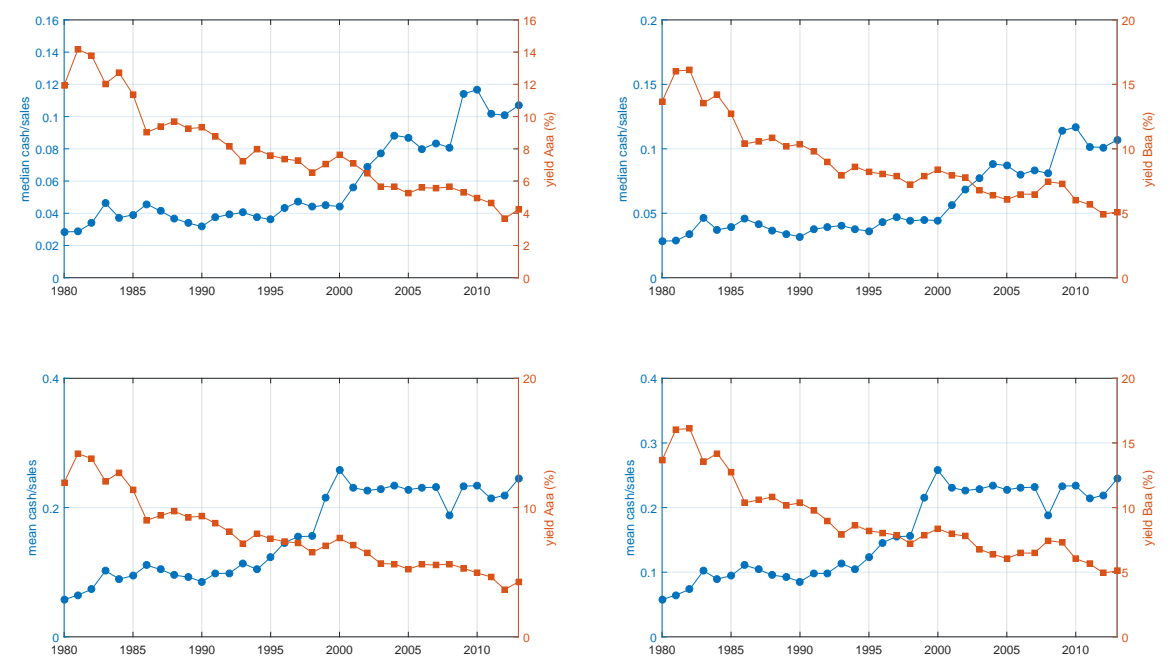

Fig. A.1: Firm cash-sales ratio over time and Aaa and Baa Moody's corporate bond yields.

\section{Aggregate transactions}

Proof. Let $\lambda_{i}\left(n_{i}\right)$ and $\mu_{i}\left(n_{i}\right)$ denote the Lagrange multipliers on (5) and (7). The first order conditions imply

$$
\begin{aligned}
P(t) c\left(t, n_{i}\right) & =\frac{e^{-\rho t} e^{R\left(T_{j i}\right)}}{\lambda\left(n_{i}\right)}, t \in\left(T_{j i}, T_{j+1 i}\right), \\
P\left(T_{j i}\right) c^{+}\left(T_{j i}, n_{i}\right) & =\frac{e^{-\rho T_{j i}} e^{R\left(T_{j i}\right)}}{\lambda\left(n_{i}\right)}, t \rightarrow T_{j i}, t>T_{j i}, \\
P\left(T_{j+1 i}\right) c^{-}\left(T_{j+1 i}, n_{i}\right) & =\frac{e^{-\rho T_{j+1 i}} e^{R\left(T_{j i}\right)}}{\lambda\left(n_{i}\right)}, t \rightarrow T_{j+1 i}, t<T_{j+1 i},
\end{aligned}
$$

$j=1,2, \ldots, i=1, \ldots I$. Similarly, $P(t) c\left(t, n_{i}\right)=\frac{e^{-\rho t}}{\mu\left(n_{i}\right)}, t \in\left(0, T_{1 i}\right), P(0) c^{+}\left(0, n_{i}\right)=\frac{1}{\mu\left(n_{i}\right)}$, and $P\left(T_{1 i}\right) c^{-}\left(T_{1 i}\right)=\frac{e^{-\rho T_{1 i}}}{\mu\left(n_{i}\right)}$. The first transfer occurs at $T_{1 i}=n_{i}$. For $M_{i}^{-}\left(n_{i}\right), Q\left(T_{1 i}\right) \lambda\left(n_{i}\right)-\mu\left(n_{i}\right) \leq$ 0 , with equality if $M_{i}^{-}\left(n_{i}\right)>0$. Therefore, the first order conditions for transactions imply that nominal transactions $P(t) c\left(t, n_{i}\right)$ decrease at the rate $\rho$ within holding periods. Together with the constraints (5) and (7), the first order conditions imply

$$
\begin{aligned}
\lambda\left(n_{i}\right) & =\frac{1}{W_{0 i}\left(n_{i}\right)+Q\left(T_{1 i}\right) M_{i}^{-}\left(n_{i}\right)} \frac{e^{-\rho n_{i}}}{\rho}, \\
\mu\left(n_{i}\right) & =\frac{1}{M_{0 i}\left(n_{i}\right)-M_{i}^{-}\left(n_{i}\right)} \frac{1-e^{-\rho n_{i}}}{\rho} .
\end{aligned}
$$




\begin{tabular}{|c|c|c|c|c|c|c|c|c|c|c|c|c|c|c|}
\hline \multicolumn{15}{|c|}{1980} \\
\hline & $\begin{array}{c}N_{i} \\
\text { (days) }\end{array}$ & $\begin{array}{l}v_{Y_{i}} \\
(\%)\end{array}$ & & $\begin{array}{c}N_{i} \\
\text { (days) }\end{array}$ & $\begin{array}{l}v_{Y_{i}} \\
(\%)\end{array}$ & & $\begin{array}{c}N_{i} \\
\text { (days) }\end{array}$ & $\begin{array}{l}v_{Y_{i}} \\
(\%)\end{array}$ & & $\begin{array}{c}N_{i} \\
\text { (days) }\end{array}$ & $\begin{array}{l}v_{Y_{i}} \\
(\%) \\
\end{array}$ & & $\begin{array}{c}N_{i} \\
\text { (days) }\end{array}$ & $\begin{array}{l}v_{Y_{i}} \\
(\%) \\
\end{array}$ \\
\hline 1 & 0,8 & 0,00 & 11 & 3,9 & 0,00 & 21 & 7,7 & 0,35 & 31 & 15,4 & 1,71 & 41 & 33,8 & 0,00 \\
\hline 2 & 1,1 & 0,00 & 12 & 4,2 & 0,00 & 22 & 8,2 & 6,66 & 32 & 16,5 & 7,16 & 42 & 37,0 & 2,27 \\
\hline 3 & 1,5 & 0,00 & 13 & 4,5 & 11,91 & 23 & 8,9 & 0,00 & 33 & 17,8 & 2,80 & 43 & 41,0 & 1,30 \\
\hline 4 & 1,9 & 0,00 & 14 & 4,8 & 0,00 & 24 & 9,5 & 0,00 & 34 & 19,1 & 1,73 & 44 & 45,4 & 3,95 \\
\hline 5 & 2,2 & 0,00 & 15 & 5,2 & 0,00 & 25 & 10,2 & 0,00 & 35 & 20,6 & 1,37 & 45 & 52,3 & 0,00 \\
\hline 6 & 2,5 & 0,00 & 16 & 5,5 & 0,00 & 26 & 10,8 & 7,89 & 36 & 22,2 & 2,17 & 46 & 59,2 & 4,08 \\
\hline 7 & 2,8 & 0,00 & 17 & 5,9 & 6,59 & 27 & 11,7 & 0,08 & 37 & 24,0 & 0,00 & 47 & 69,6 & 3,25 \\
\hline 8 & 3,1 & 0,00 & 18 & 6,2 & 4,24 & 28 & 12,6 & 1,03 & 38 & 25,7 & 8,17 & 48 & 85,6 & 1,31 \\
\hline 9 & 3,4 & 0,00 & 19 & 6,7 & 1,68 & 29 & 13,5 & 3,09 & 39 & 27,8 & 4,60 & 49 & 116,9 & 1,08 \\
\hline 10 & 3,6 & 0,00 & 20 & 7,2 & 0,06 & 30 & 14,5 & 0,00 & 40 & 30,1 & 8,99 & 50 & 202,4 & 0,48 \\
\hline \multicolumn{15}{|c|}{ Average $N=23.6$ days. } \\
\hline \multicolumn{15}{|c|}{2010} \\
\hline & $\begin{array}{c}N_{i} \\
\text { (days) }\end{array}$ & $\begin{array}{l}v_{Y_{i}} \\
(\%)\end{array}$ & & $\begin{array}{c}N_{i} \\
\text { (days) }\end{array}$ & $\begin{array}{l}v_{Y_{i}} \\
(\%)\end{array}$ & & $\begin{array}{c}N_{i} \\
\text { (days) }\end{array}$ & $\begin{array}{l}v_{Y_{i}} \\
(\%)\end{array}$ & & $\begin{array}{c}N_{i} \\
\text { (days) }\end{array}$ & $\begin{array}{l}v_{Y_{i}} \\
(\%)\end{array}$ & & $\begin{array}{c}N_{i} \\
\text { (days) }\end{array}$ & $\begin{array}{l}v_{Y_{i}} \\
(\%)\end{array}$ \\
\hline 1 & 0,6 & 0,16 & 11 & 11,5 & 0,00 & 21 & 31,4 & 0,74 & 31 & 62,1 & 2,84 & 41 & 138,1 & 1,83 \\
\hline 2 & 1,2 & 0,02 & 12 & 12,7 & 16,45 & 22 & 34,2 & 0,00 & 32 & 66,4 & 1,32 & 42 & 153,0 & 0,74 \\
\hline 3 & 1,9 & 1,23 & 13 & 14,7 & 0,00 & 23 & 37,3 & 0,00 & 33 & 71,0 & 2,06 & 43 & 168,7 & 3,28 \\
\hline 4 & 2,8 & 0,00 & 14 & 16,5 & 1,66 & 24 & 39,6 & 1,05 & 34 & 76,3 & 0,00 & 44 & 188,9 & 1,31 \\
\hline 5 & 3,8 & 0,00 & 15 & 18,4 & 0,21 & 25 & 42,1 & 3,84 & 35 & 81,6 & 11,34 & 45 & 212,3 & 5,03 \\
\hline 6 & 4,6 & 2,99 & 16 & 20,7 & 0,00 & 26 & 45,0 & 0,00 & 36 & 88,0 & 4,73 & 46 & 245,8 & 2,17 \\
\hline 7 & 5,7 & 1,24 & 17 & 22,6 & 6,30 & 27 & 47,7 & 0,68 & 37 & 95,8 & 0,97 & 47 & 292,0 & 1,31 \\
\hline 8 & 6,8 & 2,20 & 18 & 24,8 & 0,00 & 28 & 50,4 & 7,49 & 38 & 104,4 & 0,31 & 48 & 363,4 & 2,18 \\
\hline 9 & 8,5 & 0,00 & 19 & 27,0 & 0,00 & 29 & 54,0 & 2,13 & 39 & 113,2 & 3,96 & 49 & 507,4 & 2,45 \\
\hline 10 & 10,0 & 0,00 & 20 & 29,1 & 3,52 & 30 & 58,2 & 0,00 & 40 & 125,7 & 0,00 & 50 & 974,7 & 0,26 \\
\hline
\end{tabular}

Table A.1: Values of $v_{Y_{i}}$ and $N_{i}$ for each percentile $i=1, \ldots, 50$ of $m_{H_{i}}$ for 1980 and 2010 . These values were used to generate the cash-sales distributions for 1980 and 2010 in figure 7. Analogous values were calculated for the other years. The average $N$ is a weighted average of $N_{i}$ using $v_{Y_{i}}$ as weights.

The values of $M_{0 i}\left(n_{i}\right)$ and $W_{0 i}\left(n_{i}\right)$ such that the economy is in an equilibrium with constant interest rate at $t=0$ are such that (1) nominal transactions $P(t) c\left(t, n_{i}\right)$ evolve at the steady state rate and (2) all firms start a holding period with transactions $c_{0 i}$, excluding the shorter holding period from $t=0$ to $t=n_{i}$. The first order conditions imply $\pi(t)+\frac{\dot{c}\left(t, n_{i}\right)}{c\left(t, n_{i}\right)}=-\rho$. So, spending decreases at the rate $\rho$ and, in the steady state, transactions decrease at the rate $\rho+\pi=r$. For an arbitrary firm $n_{i}$, nominal transactions at $t=0$ are $P_{0} c\left(0, n_{i}\right)=P_{0} c_{0 i} e^{-r\left(N_{i}-n_{i}\right)}$, where $P_{0}$ is the price level at $t=0$ in the steady state before the shock hits the economy. The value $c_{0 i} e^{-r\left(N_{i}-n_{i}\right)}$ implies that firm $n_{i}$ makes transactions $c_{0 i}$ just after the first bond trade. Therefore, from $\int_{0}^{n_{i}} P(t) c\left(t, n_{i}\right) d t+M_{i}^{-}\left(n_{i}\right)=M_{0 i}\left(n_{i}\right)$, imposing $M_{i}^{-}\left(n_{i}\right)=0$, we obtain

$$
M_{0 i}\left(n_{i}\right)=P_{0} c_{0 i} e^{-r\left(N_{i}-n_{i}\right)} \frac{1-e^{-\rho n_{i}}}{\rho} .
$$

Analogously, $W_{0 i}\left(n_{i}\right)=\sum_{j=1}^{\infty} Q\left(T_{j i}\right) \int_{T_{j i}}^{T_{j+1 i}} P(t) c\left(t, n_{i}\right) d t$. We have $T_{j i}=n_{i}+N_{i}(j-1), j=$ $1,2, \ldots$, for the times of the transfer periods. As $Q\left(T_{j i}\right)=e^{-r T_{j i}}$ and transactions decrease at the rate $\rho$ at the steady state, then

$$
W_{0 i}\left(n_{i}\right)=P_{0} c_{0 i} \frac{e^{-\rho n_{i}}}{\rho} .
$$


Using constraints (5) and (7) with $M_{i}^{-}\left(T_{1 i} n_{i}\right)=0$ and the first order conditions, we obtain $\mu\left(n_{i}\right)=$ $\frac{1-e^{-\rho n_{i}}}{\rho M_{0}\left(n_{i}\right)}$ and $\lambda\left(n_{i}\right)=\frac{e^{-\rho n_{i}}}{\rho W_{0 i}\left(n_{i}\right)}$. Substituting $M_{0 i}\left(n_{i}\right)$ and $W_{0 i}\left(n_{i}\right)$ implies $\mu\left(n_{i}\right)=\frac{e^{r\left(N_{i}-n_{i}\right)}}{P_{0} c_{0 i}}$ and $\lambda_{i}\left(n_{i}\right)=\frac{1}{P_{0} c_{0 i}}$. The condition to verify whether $M_{i}^{-}\left(T_{1 i}\left(n_{i}\right)\right)=0$ is $\mu\left(n_{i}\right)>Q\left(T_{1}\right) \lambda\left(n_{i}\right)$, which holds as $e^{r N_{i}}>1$. Having obtained $W_{0 i}\left(n_{i}\right)$, we obtain $B_{0 i}\left(n_{i}\right)=W_{0 i}\left(n_{i}\right)-\int_{0}^{\infty} Q(t) P(t) Y_{i} d t$.

To obtain aggregate transactions, suppose an arbitrary $t \geq N_{i}$ (the argument is similar for $\left.t<N_{i}\right)$. As $t \geq N_{i}$, we know that firm $n_{i}$ has already made the first transfer. As transactions decrease at the rate $r$, we have $c\left(t, n_{i}\right)=c_{0 i} e^{-r\left(t-T_{j i}\left(n_{i}\right)\right)}$, for the highest $j\left(n_{i}\right)$ such that $T_{j i}\left(n_{i}\right) \leq$ $t<T_{j+1 i}\left(n_{i}\right)$. Firms with $n_{i} \in\left[0, t-j N_{i}\right)$ are in their $(j+1)$ th holding period while firms with $n_{i} \in\left[t-j N, N_{i}\right)$ are in their $j$ th holding period. Aggregate transactions are then given by

$$
\frac{1}{N_{i}} \int_{0}^{t-j N_{i}} c_{0 i} e^{-r\left(t-T_{j+1 i}\left(n_{i}\right)\right)} d n_{i}+\frac{1}{N_{i}} \int_{t-j N}^{N_{i}} c_{0 i} e^{-r\left(t-T_{j i}\left(n_{i}\right)\right)} d n_{i}
$$

Changing variables to $s_{i} \equiv T_{j+1 i}=n_{i}+j N_{i}$ and $s_{i} \equiv T_{j i}=n_{i}+(j-1) N_{i}$ in the first and second integrals, we obtain $C_{i}(t)=\frac{1}{N_{i}} \int_{t-N_{i}}^{t} c_{0 i} e^{-r\left(t-s_{i}\right)} d s_{i}$. With another change of variables, $C_{i}(t)=\frac{1}{N_{i}} \int_{0}^{N_{i}} c_{0 i} e^{-r x} d x$, which implies $C_{i}(t)=c_{0 i} \frac{1-e^{-r N_{i}}}{r N_{i}}$.

Cash-sales ratio

To obtain the cash-sales ratio, denoted by $m=\frac{M(t)}{P(t) Y}$, first note that aggregate cash holdings grows at the same rate of inflation in the steady state. Therefore, the cash-sales ratio is constant in the steady state. In particular, $m=\frac{M(0)}{P_{0} Y}$. At time zero, aggregate cash holdings are equal to $M(0)=\frac{1}{N_{i}} \int_{0}^{N_{i}} M_{0}\left(n_{i}\right) d n_{i}$. Substituting the values found for $M_{0}\left(n_{i}\right)$ and dividing by $P_{0} Y$, we obtain

$$
m_{i}=\frac{e^{-r N_{i}}}{\rho} \frac{r N_{i}}{1-e^{-r N_{i}}}\left[\frac{e^{r N_{i}}-1}{r N_{i}}-\frac{e^{(r-\rho) N_{i}}-1}{(r-\rho) N_{i}}\right] .
$$

Finally, as $M(0)$ and $Y$ are normalized to 1 , we obtain $P_{0}=1 / m$. With this final step, we obtain all equilibrium prices and quantities for the steady state.

Maximization problem for the transition

There are two states for the interest rate path, $s=1,2$, and there are two contingent bonds. In state 1 , the nominal interest rate path is the constant initial steady state interest rate $r$. In state 2 , the nominal interest rate is different; it is equal to the unexpected path $r(t)$. Let $\theta$ denote the probability of state 1 . For $s=1,2$, let $c\left(t, n_{i} ; s\right)$ denote consumption of entrepreneur $n_{i}$ at date $t$ in state $s$, and $T_{j, i}\left(n_{i} ; s\right)$ denote the date of the $j$ th transfer of entrepreneur $n_{i}$ in state $s$. As money is not contingent on the states, entrepreneur $n_{i}$ must use the initial stock of money $M_{0 i}\left(n_{i}\right)$ from $t=0$ until the first transfer $T_{1, i}\left(n_{i} ; s\right)$. In this framework, from $t=0$ to $T_{1, i}\left(n_{i} ; s\right)$, each entrepreneur has two cash-in-advance constraints, one for each state,

$$
\int_{0}^{T_{1, i}\left(n_{i} ; s\right)} P(t ; s) c_{i}\left(t, n_{i} ; s\right) d t+M_{0, i}^{-}\left(n_{i} ; s\right)=M_{0, i}\left(n_{i}\right), \text { for } s=1,2 .
$$

After $T_{1, i}\left(n_{i} ; s\right)$, on the other hand, there is just one intertemporal budget constraint, because entrepreneurs use contingent bonds to transfer resources between states. 
The maximization problem of each entrepreneur is

$$
\max \theta \sum_{j=0}^{\infty} \int_{T_{j, i}\left(n_{i} ; 1\right)}^{T_{j+1, i}\left(n_{i} ; 1\right)} e^{-\rho t} u\left(c_{i}\left(t, n_{i} ; 1\right)\right) d t+(1-\theta) \sum_{j=0}^{\infty} \int_{T_{j, i}\left(n_{i} ; 2\right)}^{T_{j+1, i}\left(n_{i} ; 2\right)} e^{-\rho t} u\left(c_{i}\left(t, n_{i} ; 2\right)\right) d t
$$

subject to

$$
\begin{gathered}
\sum_{s} \sum_{j=1}^{\infty} Q\left(T_{j, i}\left(n_{i} ; s\right)\right) \int_{T_{j, i}\left(n_{i} ; s\right)}^{T_{j+1, i}\left(n_{i} ; s\right)} P(t ; s) c_{i}\left(t, n_{i} ; s\right) d t \leq \sum_{s} Q\left(T_{1, i}\left(n_{i} ; s\right)\right) M^{-}\left(n_{i} ; s\right)+W_{0}\left(n_{i}\right), \\
\int_{0}^{T_{1, i}\left(n_{i} ; s\right)} P(t ; s) c_{i}\left(t, n_{i} ; s\right) d t+M_{0, i}^{-}\left(n_{i} ; s\right)=M_{0, i}\left(n_{i}\right),
\end{gathered}
$$

where $W_{0, i}\left(n_{i}\right) \equiv B_{0, i}\left(n_{i}\right)+\sum_{s=1,2} \int_{0}^{\infty} Q(t ; s) P(t ; s) Y d t$.

The first order conditions with respect to $c_{i}\left(t, n_{i}\right)$ in the state 2 imply, for $j \geq 2$,

$$
c^{+}\left(T_{j, i}\left(n_{i}\right), n_{i}\right)\left[R\left(T_{j, i}\left(n_{i}\right)\right)-R\left(T_{j-1, i}\left(n_{i}\right)\right)\right]=r\left(T_{j}\left(n_{i}\right)\right) \int_{T_{j, i}\left(n_{i}\right)}^{T_{j+1, i}\left(n_{i}\right)} \frac{P(t) c_{i}\left(t, n_{i}\right)}{P\left(T_{j, i}\left(n_{i}\right)\right)} d t,
$$

where

$$
c^{+}\left(T_{j, i}\left(n_{i}\right), n_{i}\right)=\left[\lambda\left(n_{i}\right) e^{\rho T_{j, i}\left(n_{i}\right)} Q\left(T_{j, i}\left(n_{i}\right)\right) P\left(T_{j, i}\left(n_{i}\right)\right)\right]^{-1} .
$$

For $T_{1}\left(n_{i}\right)$, the first order conditions imply

$$
c^{+}\left(T_{1}, n_{i}\right) R\left(T_{1}\left(n_{i}\right)\right)-\log \frac{\lambda\left(n_{i}\right)}{\mu\left(n_{i}\right)}+\frac{r\left(T_{1}\left(n_{i}\right)\right) M_{i}^{-}\left(n_{i}\right)}{P\left(T_{1}\left(n_{i}\right)\right)}=r\left(T_{1}\left(n_{i}\right)\right) \int_{T_{1}\left(n_{i}\right)}^{T_{2}\left(n_{i}\right)} \frac{P(t) c\left(t, n_{i}\right)}{P\left(T_{1}\left(n_{i}\right)\right)} d t .
$$

Proposition 1. Proof. First, we prove that all firms choose $M_{i}^{-}\left(n_{i}\right)=0$ under the new interest rate path $r(t)$, given the initial cash and bond holdings $M_{0 i}\left(n_{i}\right)$ and $W_{0 i}\left(n_{i}\right)$ of the first steady state. As a result the Lagrange multipliers $\lambda\left(n_{i}\right)$ and $\mu\left(n_{i}\right)$ do not change with the shock. To show this statement, we have to show that the sufficient condition for $M_{i}^{-}\left(n_{i}\right)=0$, given by $\mu\left(n_{i}\right)>Q\left(n_{i}\right) \lambda\left(n_{i}\right)$, holds for every $n_{i}$. We have

$$
\begin{aligned}
\lambda\left(n_{i}\right) & =\frac{e^{-\rho n_{i}}}{\rho\left[W_{0}\left(n_{i}\right)+Q\left(n_{i}\right) M_{i}^{-}\left(n_{i}\right)\right]}, \\
\mu\left(n_{i}\right) & =\frac{1-e^{-\rho n_{i}}}{\rho\left[M_{0}\left(n_{i}\right)-M_{i}^{-}\left(n_{i}\right)\right]}
\end{aligned}
$$

together with the first order conditions and the budget constraints. Substituting the values of $M_{0 i}\left(n_{i}\right)$ and $W_{0 i}\left(n_{i}\right)$ for the initial equilibrium, we have that the condition for $M_{i}^{-}\left(n_{i}\right)=0$ holds if and only if $e^{r\left(N_{i}-n_{i}\right)}>Q\left(n_{i}\right)$, which is always true as $Q\left(n_{i}\right)<1$ (moreover, $\mu\left(n_{i}\right)=Q\left(n_{i}\right) \lambda\left(n_{i}\right)$ cannot hold for $\left.M_{i}^{-}\left(n_{i}\right)>0\right)$.

We obtain the price level at each time with the market clearing condition for transactions. For $t \geq N_{i}$, all firms in group $i$ have already made their first bond trade. Working similarly as above, 
substituting $\lambda\left(n_{i}\right)=\frac{1}{P_{0} c_{0 i}}$, aggregate transactions for all firms in group $i$ are given by

$$
C_{i}(t)=\frac{P_{0} c_{0 i}}{N_{i}} \int_{0}^{t-j N_{i}} \frac{e^{-\rho t} e^{R\left(T_{j+1}\right)}}{P(t)} d n_{i}+\frac{P_{0} c_{0 i}}{N_{i}} \int_{t-j N_{i}}^{N_{i}} \frac{e^{-\rho t} e^{R\left(T_{j}\right)}}{P(t)} d n_{i} .
$$

For $t \geq N_{i}$, firms $n_{i} \in\left[0, t-j N_{i}\right)$ are in their $(j+1)$ th holding period and firms with $n_{i} \in\left[t-j N, N_{i}\right)$ are in their $j$ th holding period. We have, therefore,

$$
C_{i}(t)=\frac{P_{0} c_{0 i}}{N_{i}} \int_{t-N_{i}}^{t} \frac{e^{-\rho t} e^{R\left(n_{i}\right)}}{P(t)} d n_{i} .
$$

For $0 \leq t<N_{i}$, firms with $n_{i} \in[0, t)$ have already made their first bond trade and firms with $n_{i} \in\left[t, N_{i}\right)$ are in the short holding period from zero to $t=n_{i}$. Let real transactions of these two groups be denoted by $C_{i}^{1}(t)=\frac{P_{0} c_{0 i}}{N_{i}} \int_{0}^{t} \frac{e^{-\rho t} e^{R\left(n_{i}\right)}}{P(t)} d n_{i}$ and $C_{i}^{0}(t)=\frac{1}{N_{i}} \int_{t}^{N_{i}} \frac{e^{-\rho t}}{\mu\left(n_{i}\right) P(t)} d n_{i}$. Aggregate real transactions are then $C_{i}(t)=C_{i}^{1}(t)+C_{i}^{0}(t)$. As $t \rightarrow N_{i}$, the firms in group $i$ that have not made a transfer decrease, and so $C_{i}^{0}(t)$ decreases to zero. Substituting $\mu\left(n_{i}\right)=\frac{e^{r\left(N_{i}-n_{i}\right)}}{P_{0} c_{0 i}}$, we obtain

$$
C_{i}^{0}(t)=\frac{P_{0} c_{0 i} e^{-\rho t}\left(1-e^{-r\left(N_{i}-t\right)}\right)}{P(t) r N},
$$

where $r$ is the nominal interest rate before the shock. Using $\sum v_{i} C_{i}(t)=Y$, we obtain the $P(t)$ in the statement of the proposition.

Proposition 2. Proof. Without loss of generality we assume $I=1$. We get $P(0)=P_{0}$ by using the formula of $P(t)$ for $t=0$. Also, $\lim _{t \rightarrow 0} P(t)=P_{0}$, which shows that $P(t)$ is continuous at $t=0$, and so does not jump at the time of the shock. When $t<N_{1}$ the derivative of $P(t)$ with respect to $t$ is $\dot{P}(t)=k\left[-\rho e^{-\rho t} \int_{0}^{t} e^{R(n)} d n+e^{-\rho t} e^{R(t)}-\frac{\rho e^{-\rho t}+(r-\rho) e^{(r-\rho) t} e^{-r N}}{r}\right]$, where $k$ is a constant. So, inflation just after the shock remains equal to inflation before the shock, $\pi(0)=r-\rho=\pi$ for any $r(t)$. As the real interest rate before the shock is $\rho$, we have $\operatorname{rr}(0)-\rho=r(0)-r$. We have

$$
r r(t)=r(t)-\pi(t) \Rightarrow r r(t)=\rho+r(t)-\frac{e^{R(t)}-e^{R\left(t-N_{I}\right)}}{\int_{t-N_{I}}^{t} e^{R\left(n_{i}\right)} d n_{i}},
$$

using the formula of $P(t)$ for $t \geq N_{I}$. We obtain $\lim _{N \rightarrow 0} r r(t)=\rho+r(t)-r(t)=\rho$, which implies that the real interest rate is constant for any $r(t)$ if there is no market segmentation and, consequently, no heterogeneity in the distribution of cash holdings. 